\title{
The cloud-aerosol-radiation (CAR) ensemble modeling system
}

\author{
X.-Z. Liang ${ }^{1,2}$ and F. Zhang $^{2}$ \\ ${ }^{1}$ Department of Atmospheric and Oceanic Science, University of Maryland, College Park, MD 20742-2425, USA \\ ${ }^{2}$ Earth System Science Interdisciplinary Center, University of Maryland, College Park, MD 20740-3823, USA
}

Correspondence to: X.-Z. Liang (xliang@umd.edu)

Received: 12 March 2013 - Published in Atmos. Chem. Phys. Discuss.: 19 April 2013

Revised: 17 June 2013 - Accepted: 14 July 2013 - Published: 22 August 2013

\begin{abstract}
A cloud-aerosol-radiation (CAR) ensemble modeling system has been developed to incorporate the largest choices of alternate parameterizations for cloud properties (cover, water, radius, optics, geometry), aerosol properties (type, profile, optics), radiation transfers (solar, infrared), and their interactions. These schemes form the most comprehensive collection currently available in the literature, including those used by the world's leading general circulation models (GCMs). CAR provides a unique framework to determine (via intercomparison across all schemes), reduce (via optimized ensemble simulations), and attribute specific key factors for (via physical process sensitivity analyses) the model discrepancies and uncertainties in representing greenhouse gas, aerosol, and cloud radiative forcing effects.

This study presents a general description of the CAR system and illustrates its capabilities for climate modeling applications, especially in the context of estimating climate sensitivity and uncertainty range caused by cloud-aerosolradiation interactions. For demonstration purposes, the evaluation is based on several CAR standalone and coupled climate model experiments, each comparing a limited subset of the full system ensemble with up to 896 members. It is shown that the quantification of radiative forcings and climate impacts strongly depends on the choices of the cloud, aerosol, and radiation schemes. The prevailing schemes used in current GCMs are likely insufficient in variety and physically biased in a significant way. There exists large room for improvement by optimally combining radiation transfer with cloud property schemes.
\end{abstract}

\section{Introduction}

Future climate prediction biases and inter-model discrepancies among general circulation models (GCMs) depend critically on the large uncertainties existing in climate sensitivity that in turn are dominated by the wide spreads of cloud radiative feedbacks simulated (Cess et al., 1996; Stott and Kettleborough, 2002; Del Genio et al., 2005; Zhang et al., 2005; Webb et al., 2006; Bony et al., 2006; Cash et al., 2007; Kay et al., 2012). Such spreads result from different parameterization schemes of uncertain subgrid (unresolved) processes, all being equally justifiable by current observational data and physical understandings. GCMs' parameterization advances over the past few decades have not narrowed the wide range of uncertainties in predicting cloud feedbacks under climate change (Del Genio et al., 2005; Zhang et al., 2005). They are further complicated by substantial errors in aerosol direct and indirect forcings (Lohmann and Feichter, 2005), and even in greenhouse gas (GHG) effects (Collins et al., 2006) and atmospheric absorptance independent of clouds (Wild et al., 2006).

We therefore have most recently built the innovative cloud-aerosol-radiation (CAR) ensemble modeling system that consists of the largest collection of alternate mainstream parameterizations for cloud properties (cover, water, radius, optics, geometry), aerosol properties (type, profile, optics), radiation transfers (solar, infrared), and their interactions currently available in the literature. As such, CAR integrates, and thus facilitates, the intercomparison of the numerical representations of interactions among cloud, aerosol, and radiation that are most commonly available in the modeling community. When coupled with a climate model that predicts the life cycle of clouds and aerosols using various approaches, CAR provides a unique tool for systematic 
understanding and quantification of inter-model differences that span a broad range of climate prediction errors and uncertainties due to model formulation deficiencies.

Several studies have documented substantial biases (against observational estimates) and inter-model spreads among GCMs in simulating total radiative fluxes (Wild, 2005; Li et al., 2013), and their associated quantities, including cloud amounts (Zhang et al., 2005), cloud water paths (Li et al., 2008, 2011a; Waliser et al., 2009), and cloud radiative forcings (CRFs) (Pincus et al., 2008; Ichikawa et al., 2012). In general, total flux discrepancies can be attributed to formulation differences in cloud properties, including cover fraction, water path, optical characteristics, and subgrid structure (horizontal variability plus vertical overlap), gaseous and aerosol effects, as well as radiative transfer algorithms. Comparisons among GCMs' simulations, however, cannot separate these contributing factors as they all strongly depend on model climate state biases and are individually represented by different schemes across the models. The factor attribution is a challenging but critical issue that has motivated several major projects comparing GCM radiation codes against 1-D line-by-line model (LBL) or 3-D Monte Carlo photon transport (MC) simulations under specific idealized conditions. These include Ellingson et al. (1991) and Fouquart et al. (1991) for synthetic clear and overcast cases, Barker et al. (2003) for cloud-resolving-model (CRM) generated subgrid clouds, Collins et al. (2006) for GHG effects, and Oreopoulos et al. (2012) for observed clear and overcast cases. None of these comparisons has differentiated total radiation code inaccuracy into component error sources. Only most recently, Zhang et al. (2013) was able to do so using the CAR system under realistic climate conditions over the globe. They concluded that the treatment for unresolved cloud structures is the dominant source for the model spreads of CRFs and radiative fluxes, explaining over $40-50 \%$ of the total.

Another challenging issue is to separate uncertainties that are beyond the current model ability or computational resource from errors that can be contained by the existing observational data. The radiation transfer modeling with detailed spectral resolution has little uncertainty if the problem is fully specified; that is, all input quantities including clouds, gases, and aerosols are exactly defined. Optical properties of clouds and aerosols can be determined if their compositions and habits are known. Radiation accuracy can be evaluated against the LBL references for clear or overcast conditions and the MC results for fractal clouds. And 1-D radiative transfer algorithms converge as the angular resolution increases. However, a full specification of the problem is impossible in any GCM where approximations and parameterizations for unresolved processes are inevitably and commonly used to balance physical accuracy with computational cost. As such, substantial discrepancies exist in all input variables. For example, significant disagreements of cloud properties exist among the modern GCMs in both magnitudes and spatial patterns. Most often models tend to simulate cloud liquid and ice water paths much larger than the observed estimates (Li et al., 2011a, 2012), while they underestimate cloud fractions considerably (Zhang et al., 2005; Waliser et al., 2009). These deficiencies must be compensated with more optically thick clouds than in reality to achieve a radiative balance at the top of atmosphere (TOA) close to observations. This model tuning, while necessary, has too many degrees of freedom unconstrained due to the lack of credible observations for subgrid cloud structural information, including vertical distribution and horizontal variability of cloud cover, water content, and particle habit. As a result, GCMs choose specific parameterization schemes for clouds and aerosols that vary widely among their coupled radiation packages. None of these schemes are created equal, nor are they identified with clear advantages. They are alternate mainstream choices equally justifiable by the current state of scientific knowledge and computing power. Strictly speaking the model spreads that result from these different choices are not all uncertainties but partially errors. This study does not distinguish between the two, but considers the total as uncertainties in general from the perspective of their consequences on the GCMs' climate prediction range.

Model tuning is usually a subjective and convergent practice. Most often a model is built upon its existing structural configuration and improved from that by changing only adjustable parameters when found necessary. Some models are known to ignore certain physics processes - for example, neglecting particular absorbers (Collins et al., 2006) or longwave scattering effects (Oreopoulos et al., 2012). As such, there are substantial disparities among the major GCM codes in representing cloud, aerosol, and radiation processes, where outdated formulations are still in use. Comparison of model outputs on these processes cannot reveal the true uncertainty but rather the errors due to model physics inadequacy. Errors in different model components can cancel, as demonstrated by Zhang et al. (2013) using CAR in an attribution analysis of CRF spreads. Inadequate observational data or their disjointed model interpretation can obfuscate model formulation deficiencies, and thus hamper the GCM development and validation effort (Waliser et al., 2009). Using the same data for model tuning and evaluation raises the question of circular reasoning, while the agreement (or lack thereof) among models tuned against the same data of unknown accuracy can mislead the assessment of numerical schemes representing the correct physics. Tuning to closely match observations also implies that these models cannot be considered independent. All these issues are important. But it is beyond the scope of this study to separate their contributions into either overall model biases or inter-model spreads. Nonetheless, it is likely that current GCMs do not completely represent the true climate system and that their diversities cover a minimum rather than the full range of uncertainties (Tebaldi and Knutti, 2007). By the same argument, the CAR system is not designed to represent the full range of uncertainties 
identified with the cloud, aerosol, and radiation processes, but to significantly expand that range by incorporating the largest collection of parameterization schemes available in the major GCMs worldwide.

Tebaldi and Knutti (2007) presented a comprehensive overview of GCM climate prediction uncertainties, grouped into sources from initial condition, boundary forcing, parameterization parameter, and model structure. Most relevant to this study are the last three kinds. The forcing uncertainty is introduced when surface albedo, surface emissivity, and solar insolation as well as atmospheric GHG and aerosol concentrations are prescribed over time. CAR handles this uncertainty through a special external forcing module (see below) that includes the best available observational estimates and alternate scenarios of GHG emissions depicting the possible future world's economic and social development pathways. The parametric uncertainty stems from the necessity to parameterize subgrid process effects with bulk formulae in terms of model-resolved variables. Parameterization schemes contain parameters that are uncertain from observations or physical principles. Such uncertainty can be explored by the perturbed physics ensemble (PPE) simulations of a single GCM but with various choices for selected parameters (Murphy et al., 2004; Stainforth et al., 2005). The PPE result, however, can strictly differ between GCMs that employ different schemes with parameters defined differently, and yield varying climate sensitivity through nonlinear interactions (Sanderson, 2011). This sensitivity, usually called the structural uncertainty as caused by choices in the model design, goes beyond the ability of the PPE method changing values for particular parameters. It can be quantified by comparing alternate schemes among multiple GCMs. This is one of the main motivations for developing the CAR ensemble system that incorporates the most comprehensive collection of physics parameterization schemes currently available and the true plug-and-play interface for adoption into most modern GCMs. The system allows for free choice of the built-in parameterization schemes in their entirety that all are used by current GCMs and have individually already been optimized in certain ways to produce overall performance comparable within observational uncertainties.

Therefore, the CAR system is designed to capture a wide range of the forcing, parametric, and structural uncertainties that are identified with the mainstream parameterization schemes for cloud, aerosol, and radiation processes in the modern GCMs. This range, while likely the largest one at the present, still cannot be considered as the full expectation of actual probabilities due to various model-tuning issues discussed earlier. The application of the complete CAR ensemble is also not practical. In particular, as any radiative energy imbalance may cause a coupled GCM to produce systematic climate drift, in order to simulate a reasonable climate state, substantial tuning must be taken before a certain combination of the cloud, aerosol, and radiation schemes is chosen. More problematic is that such an integrated package strongly de- pends on the host-GCM-predicted atmospheric states (e.g., water vapor, liquid, ice concentrations) that determine the cloud and aerosol properties. Thus neither all combinations built in the CAR system nor a specific package from a particular GCM can be simply adopted for other GCMs without significant retuning. Such shortcomings must be kept in mind when interpreting the results for all the experiments presented below, where a small subset of the CAR ensemble is used.

This study presents a general model description and basic skill evaluation of the CAR ensemble modeling system. The evaluation is based on several experiments to highlight some key features of CAR. These include specific cases for the conventional radiation code intercomparison, GHG radiative forcing estimates for the recent IPCC future projections, clear and cloud radiative forcing distributions over the globe with and without aerosol effects as driven by the observational reanalysis of the climate in 2004, and climate effects due to cloud-aerosol-radiation interactions using a continuous integration during 2004 of CAR as fully coupled with the regional Climate-Weather Research Forecast model (CWRF) (Liang et al., 2012) over the US. Each experiment compares a large number of alternate schemes, up to 896 combinations. This is, however, still an extremely limited subset of the full CAR ensemble. They are designed not to fully explore interactions among all schemes, and interpretation of their results is largely constrained by our specific choice of these schemes that are commonly used in current GCMs. These comparisons do, however, depict the critical dependence of radiative fluxes on combinations of specific schemes for the cloud, aerosol, and radiation components, and thus a large range of diversities among GCMs in representing their interactions. They aim mainly to illustrate the capabilities of CAR for climate prediction, especially in the context of climate sensitivity and model spread caused by cloud-aerosolradiation interactions.

\section{Brief model description}

Figure 1 illustrates the current CAR physics options and executing structure (see all the abbreviations and acronyms listed before the references). The system incorporates seven major complete cloud-aerosol-radiation packages from the latest global weather forecast and climate prediction models used in the key operational centers and research institutions worldwide. These include cam (NCAR) (Collins et al., 2004), rrtmg (NCEP, ECMWF, future NCAR) (Clough et al., 2005; Iacono et al., 2008; Morcrette et al., 2008), gfdl (NOAA) (Freidenreich and Ramaswamy, 1999; Schwarzkopf and Ramaswamy, 1999; Clough et al., 1992), gsfc (NASA) (Chou and Suarez, 1999; Chou et al., 2001), cccma (Canada) (Li, 2002; Li and Barker, 2005), cawcr (Australia, also future UKMO) (Sun and Rikus, 1999; Sun, 2008), and flg (popular for DOE/ARM) (Fu and Liou, 1992; Fu et al., 1998; Liou et 


\section{Cloud-Aerosol-Radiation Ensemble Modeling System}

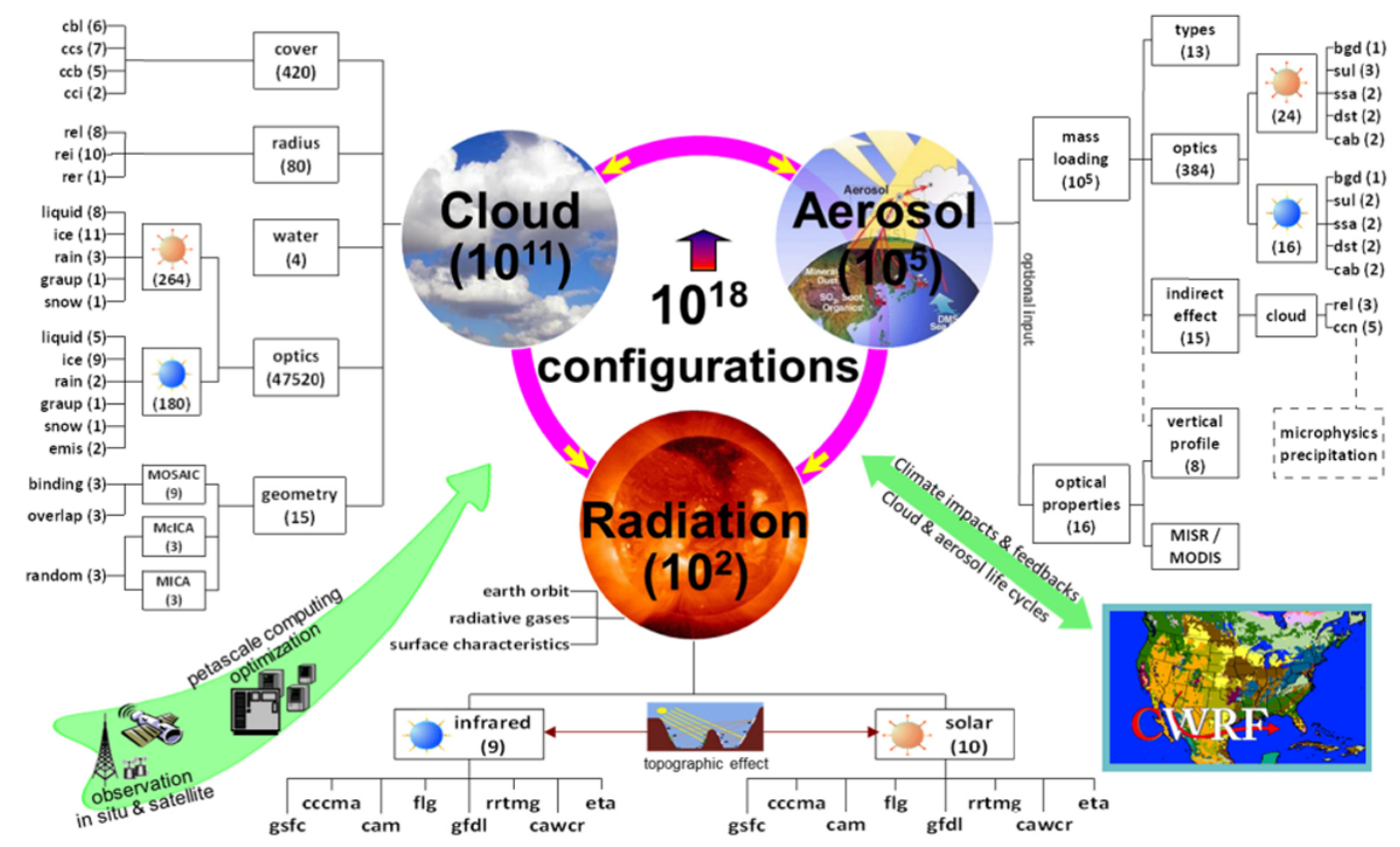

Fig. 1. Schematic of the interactive cloud-aerosol-radiation ensemble model (CAR), illustrating all key groups of parameterizations currently available (each with a number of schemes listed in parentheses) and their links with directional data flow by arrows. Shown also are petascale computing optimization against in situ and satellite observations for ensemble size reduction, as well as the full coupling with CWRF for integration of impacts to and feedbacks from climate variations over the US, where the interactive system evaluation is presented here.

al., 2008; Gu et al., 2011). It also contains other relatively simple packages often used in regional mesoscale modeling like the WRF. In addition, CAR can be coupled with a modern regional climate model (RCM) or global GCM that predicts the cloud and aerosol lifecycles to integrate interactions among cloud, aerosol, and radiation processes as well as their climate impacts and feedbacks. Such a coupled system offers a unique tool to objectively quantify the probability distribution of model climate sensitivities, defining its likelihood and uncertainty, and thus provides more credible probabilistic climate prediction or climate change projection. As a demonstration, this study couples CAR with CWRF to evaluate the regional climate sensitivities over the US.

CAR separates all available cloud-aerosol-radiation packages from internally hard-wired codes into seven distinct modules to facilitate the true plug-and-play capability among individual parameterizations. It incorporates three main drivers (cloud, aerosol, radiation) to provide the hubs for mastering all alternate parameterizations for cloud properties (cover, water, radius, geometry); aerosol properties (type, profile) and radiation transfers (solar, infrared); three couplers (cld_2_rad for cloud optics, aer_2 rad for aerosol optics, aer_2_cld for aerosol impacts on cloud droplet nucleation) to interface their interactions (cloud radiative forcings, aerosol direct and indirect effects) across all spectral bands; and one external (rad_ext) to manage all external forcings, such as solar insolation, Earth orbit variations, GHG concentrations, aerosol loading, surface albedo, surface emissivity, and topographic impacts, all of which can be predicted via coupling with other modules or specified by data inputs.

Given the modular design, CAR enables all built-in cloud and aerosol parameterizations selectable and fully exchangeable to operate effectively with all radiation transfer schemes. It also allows for us to easily implement numerous new parameterizations available in the literature (not in the listed packages) and to do so as advances continue. Thus, CAR depicts the most comprehensive numerical representation for the state-of-the-science understandings on nonlinear interactions among cloud, aerosol, and radiation. It includes free choices of alternate parameterization schemes for cloud cover (420), water (4), geometry ${ }^{1}(15)$, and effective particle radius/size (80); cloud optics for solar (264) and infrared

1 The term geometry is used here to describe the configuration of clouds with subgrid variability. As discussed in Liang and Wang (1997), for GCM parameterization the subgrid variability related to cloud-radiation interaction includes not only the cloud geometric association (vertical overlap or more general macrogrouping) and inhomogeneity (within-cloud optical property variance) that have already been built in CAR, but also broken-cloud effects (interaction between finite clouds, i.e., mutual shielding and reflection) to be developed in the future. 
(180); aerosol types (13) and vertical profiles (8); aerosol optics for solar (24) and infrared (16); aerosol indirect effects (15); radiation transfer for solar (10) and infrared (9). In total, the present CAR ensemble can model over $10^{18}$ variations of cloud, aerosol, and radiation interactions. As discussed earlier, not all of these variations can be applied because significant system tuning must be made to ensure that the total radiative balance in the coupled GCM closely matches observations and thus dramatically constrain the acceptable combinations of the component schemes. It is also impractical to run all variations and analyze their output of astronomical scale, calling for the necessity of dimension reduction of the system (see discussion in Sect. 5). Details of individual schemes and their respective references are given online at http://car.umd.edu. When coupled with a climate model, CAR can be used to determine (via intercomparison across all schemes) or reduce (via the optimized ensemble integration) the range of the uncertainties caused by the cloudaerosol-radiation interactions likely to occur under the best observational constraints. This range accounts for most of the spread in climate sensitivities among the current prediction models, and consequently their climate change projections (IPCC, 2007).

Current climate models predict cloud cover fractions and hydrometeor concentrations only in discrete vertical layers, but do not explicitly specify cloud vertical geometric association or horizontal optical variability. As such, clouds are conventionally considered to be horizontally homogeneous within a model grid and to follow various vertical overlap assumptions for a single radiation transfer calculation using an independent column approximation (ICA). The CAR system has built in several most common schemes for cloud geometric association or vertical overlap: maximum, random, and mixed (Manabe and Strickler, 1964; Geleyn and Hollingsworth, 1979; Chou et al., 1998; Collins, 2001). The maximum overlap assumes that cloud layers are tightly associated and stack on each other to generally underestimate total cloud cover. In contrast, the random overlap assumes that all cloud layers are independent, and tends to overestimate total amount as it neglects cloud geometric association. For the intermediate, the mixed overlap assumes that adjacent cloudy layers share maximum overlap, while discrete clouds are randomly overlapped. Neither of these is likely to give the actual total cloud fraction as jointly covered by all cloud layers. To alleviate this problem, Hogan and Illingworth (2000) introduced a weighting parameter $\alpha$ to linearly combine the cloud fractions under the respective maximum and random overlap assumptions. This approach has since been adopted in several GCM parameterizations (Bergman and Rasch, 2002; Pincus et al., 2005). Empirical evidence (see review by Astin and Di Girolamo, 2006) suggests that $\alpha$ decreases exponentially with increasing separation distance between cloud layers, with the actual rate dependent on the synoptic regime and area size of calculation.
More importantly, CAR has incorporated two advanced approaches that can explicitly represent subgrid cloudradiation interactions: the mosaic treatment (Liang and Wang, 1997) and the Monte Carlo independent column approximation (McICA) (Barker et al., 2002; Pincus et al., 2003; Räisänen et al., 2004). Both approaches decouple the determination of cloud structure from the calculation of radiative transfer. Thus, the distribution of clouds and optical properties within a model grid column can be more flexibly made and consistently applied to calculate radiative fluxes and heating rates across all alternate parameterizations for both shortwave and longwave. The major difference is that the mosaic treatment distinguishes geometric associations of cloud genera differing in formation mechanisms, and thus specific of synoptic regimes as emphasized by Rossow et al. (2005) and Naud et al. (2008), whereas McICA typically employs some stochastic cloud generators that assume all cloud types to follow the same statistical relationship such as $\alpha$-weighted maximum/random overlap. The McICA contains computational burden of the full ICA treatment by performing only one ICA radiative transfer calculation for each spectral band using a different subcolumn, which in turn introduces random (unbiased) errors into the instantaneous fluxes. In addition, CAR depicts the radiative effects of subgrid optical variability by modifying cloud water content with a reduction factor that is uniform (Cahalan et al., 1994) or dependent on total cloud cover (Liang and $\mathrm{Wu}, 2005$ ), or by applying a renormalization algorithm for optical depth, singlescattering albedo, and asymmetry factor distributed over the globe from ISCCP retrievals (Cairns et al., 2000; Rossow et al., 2002). Clearly these overlap, and inhomogeneity treatments, now working consistently for all the major radiative transfer schemes, will allow for us to more rigorously evaluate the subgrid cloud radiative effects and ultimately find a cost-effective solution.

CAR has the ability to incorporate either modeled (CMIP, AEROCOM, CMAQ, WRF-Chem, CAM-Chem, GEOSChem) 3-D aerosol mass loadings and optical properties or observed (MISR, MODIS) 2-D aerosol optical depth distributions. In particular, it can now account for radiative effects of sulfate, volcanic aerosol, fine sea salt, coarse sea salt, dust $(0.1-1.0 \mu \mathrm{m})$, dust $(1.0-2.5 \mu \mathrm{m})$, dust $(2.5-5.0 \mu \mathrm{m})$, dust $(5.0-10.0 \mu \mathrm{m})$, hydrophobic black carbon, hydrophilic black carbon, hydrophobic organic carbon, hydrophilic organic carbon, and background aerosol. There are also built-in options for various vertical profile assumptions to construct 3-D aerosol distributions. Moreover, CAR includes five parameterization schemes for the aerosol 1st indirect effect: those of Martin et al. (1994), Ming et al. (2006), Nenes and Seinfeld (2003), Chuang et al. (2002), and Abdul and Ghan (2002). In these schemes, cloud condensation nuclei $(\mathrm{CCN})$ concentrations are parameterized as explicit functions of certain prescribed aerosol size distributions. Furthermore, CAR adopts a new parameterization scheme of Li et al. (2011) for water cloud optical properties with internal 
mixture of black carbon to enable a more realistic estimation of the semidirect effect. It is based on the perturbation technology to add the in-cloud extra solar heating from the internal mixture of black carbon without changing the existing cloud optical properties.

An advancement built into CAR is its ability to use, by a simple switch, either instantaneous or average states resulting from the cloud and aerosol drivers as well as other external forcings in order to provide input for the radiation driver. This is done seamlessly, without declaring additional global arrays or allocating extra memory overhead. In the past, these input variables often take the instant states at the time just before calling the radiation packages; some, but not all, variables may be given as averages between two consecutive radiation calls, causing inconsistent accounting with the rest. Since radiation calculation dominates total model physics CPU usage, it is generally called at a reduced frequency, such as half an hour or longer. We may want to use all input variables averaged consistently over that window. By default, the cloud and aerosol drivers generally are called at every dynamic step, much shorter than the radiation time interval in which they are averaged. Meanwhile, the cosine solar zenith angle (determining solar insolation) is integrated analytically over the hour angle, and thus most accurate for that window. An average approach such as this may help address the energy conservation issue, especially in accounting for cloud radiative forcings.

The CAR external forcings, handled by the rad_ext module, include the model top and surface boundary conditions, as well as GHG concentrations or aerosol loadings. They can be specified by users with options for online prescription and consistently applied to all radiation schemes. For the top boundary condition, CAR incorporates a common utility library to compute solar insolation variations based on the planetary orbital parameters of Berger et al. (1993), which are valid for millions of years into the past and future. The library includes the Earth-Sun distance factor, solar declination angle, solar hour angle at the Greenwich meridian, solar azimuth angle from the north, and cosine of solar zenith angle. These variables can be calculated with values at an instant in time or averaged over a duration using an analytic solution. This facilitates consistent climate modeling for the past and into the future.

Surface albedo and emissivity are two key radiative parameters affecting the Earth's climate. CAR incorporates the land surface albedo parameterization (depending on solar zenith angle, soil moisture, and vegetation properties) based on MODIS retrievals as developed by Liang et al. (2005) and the recent update for the black snow effects (Flanner et al., 2007). The parameterization determines albedos separately for direct and diffuse radiation at the visible (0.4$0.7 \mu \mathrm{m})$ and near-infrared $(0.7-5.0 \mu \mathrm{m})$ bands. These values are interpolated with insolation-weighted spectral integration to the specific bands of each radiation scheme. CAR specifies the land surface emissivity by the UW-Madison monthly mean data based on MODIS retrievals fitting with laboratory measurements as developed by Seemann et al. (2008). Over oceans, the albedo for open water or snow on sea ice is parameterized as in Briegleb (1992), while the emissivity is prescribed as 0.97 or specified by users for water, snow, or ice. In addition, complex topography affects surface radiation fluxes by its subgrid factors, including slope aspect, slope angle, sky view, and shadowing. CAR considers these effects following the parameterization of Müller and Scherer (2005) and Senkova et al. (2007) as implemented by Liang et al. (2006).

CAR allows for users to determine long-lived $\mathrm{GHG}\left(\mathrm{CO}_{2}\right.$, $\mathrm{CH}_{4}, \mathrm{~N}_{2} \mathrm{O}, \mathrm{CFCs}, \mathrm{CCl}_{4}, \mathrm{O}_{2}, \mathrm{CO}, \mathrm{NO}, \mathrm{SO}_{2}, \mathrm{NO}_{2}, \mathrm{CH}_{3} \mathrm{Cl}$ ) volume mixing ratios, as well as $\mathrm{O}_{3}$ and aerosol distributions. For each of $\mathrm{CH}_{4}, \mathrm{~N}_{2} \mathrm{O}$, and $\mathrm{CFCs}$, the CAM scaling is adopted to reduce the mixing ratio in the stratosphere from its constant specified in the troposphere by a factor depending on latitudes and gas species (Kiehl et al., 1998). This produces a more realistic stratospheric distribution of these trace gases. By default, CAR specifies daily $\mathrm{O}_{3} 3-\mathrm{D}$ distributions via interpolation from the monthly climatology based on satellite and ozonesonde measurements (Liang et al., 1997), and daily aerosols as defined by their optical depth and single-scattering albedo geographic distributions from the MISR satellite retrievals (Kahn et al., 2007) with certain vertical scaling. To facilitate application for climate change research and assessment, the rad_ext module has built in time-varying GHG and aerosol concentrations during the period 1970-2100 under all major IPCC scenarios of the SRES emissions (Nakicenovic et al., 2000) and the next generation representative concentration pathways (RCPs) (Moss et al., 2010). Each of these scenarios, if selected, can automatically generate the corresponding gas or aerosol concentrations at a specific date.

\section{Experiment design and evaluation data}

The CAR ensemble modeling system has a wide range of applications. It is impossible to fully evaluate CAR for all applications. In this study, five model experiments were conducted to evaluate CAR's performance in simulating standard reference cases and observational cloud and radiative fluxes, as well as to quantify and understand result differences among a suite of the alternate schemes that are frequently used in modern GCMs and RCMs. Together, the evaluation offers a basic assessment of CAR's modeling capabilities and an estimate range of model spreads associated with cloud, aerosol, and radiation calculations and their climate effects.

Note that the main objective of this study is to introduce the CAR system, with an overview of its model formulations and an illustration of its possible applications. As such, all experiments designed here are preliminary examples rather than complete endeavors that can quantify the likely range of uncertainties associated with cloud, aerosol, and radiation 
Table 1. The CIRC Phase I cases and experiment design for CAR radiative transfer accuracy.

\begin{tabular}{|c|c|c|c|c|}
\hline \multirow[t]{2}{*}{ Case } & \multirow[t]{2}{*}{ Date (site) } & \multirow[t]{2}{*}{ Weather condition } & \multicolumn{2}{|c|}{ Experiment } \\
\hline & & & LW (105 runs) & SW (147 runs) \\
\hline 1 & 9/25/2000 (SGP) & clear, dry & 7 rads & $7 \mathrm{rads}$ \\
\hline 2 & $7 / 19 / 2000$ (SGP) & clear, moist & $7 \mathrm{rads}$ & $7 \mathrm{rads}$ \\
\hline 3 & 5/04/2000 (SGP) & clear, moderately moist & $7 \mathrm{rads}$ & 7 rads \\
\hline 4 & 5/03/2004 (NSA) & clear, very dry & $7 \mathrm{rads}$ & $7 \mathrm{rads}$ \\
\hline 5 & 5/03/2004 (NSA) & as case 4 , double $\mathrm{CO}_{2}$ & $7 \mathrm{rads}$ & $7 \mathrm{rads}$ \\
\hline 6 & $3 / 17 / 2000$ (SGP) & thick cloud water path cwp $=263.4 \mathrm{gm}^{-2}$ & $\begin{array}{l}\text { different radiation-cloud } \\
\text { components among }\end{array}$ & $\begin{array}{l}\text { different radiation-cloud } \\
\text { components among }\end{array}$ \\
\hline & & & 7 rads by 5 lwls & 7 rads by 8 swls \\
\hline 7 & 7/06/2006 (PYE, AMF) & thin cloud water path, $\mathrm{cwp}=39.1 \mathrm{gm}^{-2}$ & $\begin{array}{l}\text { different radiation-cloud } \\
\text { components among }\end{array}$ & $\begin{array}{l}\text { different radiation-cloud } \\
\text { components among }\end{array}$ \\
\hline & & & 7 rads by 5 lwls & 7 rads by 8 swls \\
\hline
\end{tabular}

Site SGP: Southern Great Plain; NSA: Northern Slope of Alaska;

PYE: Pt. Reyes (California); AMF: ARM Mobile Facility.

rad 7 CAR major radiation transfer schemes:

gsfc: Chou and Suarez (1999); Chou et al. (2001)

cccma Li (2002); Li and Barker (2005)

cam Collins et al. (2004)

flg: Fu and Liou (1992); Fu et al. (1998); Gu et al. (2011); Liou et al. (2008)

gfdl: Schwarzkopf and Ramaswamy (1999); Freidenreich and Ramaswamy (1999)

rrtmg: Clough et al. (2005); Iacono et al. (2008); Morcrette et al. (2008)

cawcr: Sun and Rikus (1999); Sun (2008)

lwl 5 CAR LW cloud liquid optical property schemes:

$\mathrm{Fu}$ and Liou (1992)

Chou et al. (2001)

Dobbie et al. (1999); Lindner and Li (2000)

$\mathrm{Hu}$ and Stanmes (1993) look-up tables

Hu and Stanmes (1993)

swl 8 CAR SW cloud liquid optical property schemes:

Fu and Liou (1992)

Chou and Suarez (1999)

Dobbie et al. (1999); Lindner and Li (2000)

$\mathrm{Hu}$ and Stanmes (1993) look-up tables

Kiehl et al. (1996)

Chou and Suarez (1999)

Slingo (1989)

Hu and Stanmes (1993)

representations. For the latter to be realized, extensive simulations under realistic climate conditions over the globe must be conducted to examine a much greater subset of the CAR ensemble constrained by credible observations. This requires substantial computational resources and targets for future studies. To provide a reasonable initial evaluation, these examples are based on the mainstream schemes that are employed in the current GCMs, especially those of CMIP5 for the latest IPCC assessment.

Li et al. (2013) summarized cloud microphysics and cloud cover fraction schemes used in the CMIP5 GCMs (their Table 1b). Except for one model still using a diagnostic approach for cloud liquid water, all GCMs explicitly predict mixing ratios of cloud condensate, about half of these sep- arating liquid and ice, and the rest giving only total water. Given these predicted grid-mean condensate mixing ratios, cloud cover fractions are determined mostly using a diagnostic approach with about half of PDF-based subgrid variability, and the rest assuming a homogeneous distribution. Only three GCMs use a prognostic approach to predict cloud cover, and CWRF is implementing one such scheme following Tiedtke (1993), Tompkins (2002), and Watanabe et al. (2009). CAR incorporates both kinds of diagnostic cloud cover schemes and, when coupled with CWRF that includes a dozen of explicit cloud microphysics schemes (Liang et al., 2012) and the future prognostic cloud cover scheme, provides a comprehensive simulator to address the structured uncertainty that may result from cloud-radiation effects and 
Table 2. The experiment design for CAR cloud radiative forcing distributions.

\begin{tabular}{|c|c|c|c|c|}
\hline \multicolumn{3}{|c|}{ Cloud/radiation components } & \multicolumn{2}{|c|}{ Schemes selected } \\
\hline \multirow{7}{*}{\multicolumn{2}{|c|}{ cloud cover fraction }} & stratiform (ccs) & 1 & Xu and Randall (1996) \\
\hline & & & 2 & Slingo (1987) \\
\hline & & cirrus (cci) & 2 & Slingo (1987) \\
\hline & & boundary (cbl) & 1 & Slingo (1987) \\
\hline & & deep cumulus (ccb) & 3 & Slingo (1987) \\
\hline & & & 5 & Ferrier et al. (2002) \\
\hline & & total: ctot & 1 & based on ccs,cci,cbl,ccb \\
\hline \multicolumn{2}{|l|}{ cloud water path (cwp) } & & 2 & based on inputted cloud water mass mixing ratio \\
\hline \multirow{4}{*}{\multicolumn{2}{|c|}{ cloud droplet size }} & liquid (rel) & 1 & Savijärvi et al. (1997) \\
\hline & & & 3 & Min and Harrison (1996) \\
\hline & & ice (dei) & 2 & Sun and Rikus (1999) \\
\hline & & & 7 & Based on air temperature from GFDL \\
\hline \multirow[t]{8}{*}{ cloud optical property } & LW & liquid (lwl) & 2 & Chou et al. (2001) \\
\hline & & & 3 & Dobbie et al. (1999); Lindner and Li (2000) \\
\hline & & ice (lwi) & 106 & Fu et al. (1998) \\
\hline & & & 5 & Edwards et al. (2007) \\
\hline & SW & liquid (swl) & 3 & Dobbie et al. (1999); Lindner and Li (2000) \\
\hline & & & 6 & Chou and Suarez (1999) \\
\hline & & ice (swi) & 106 & Fu et al. (1998) \\
\hline & & & 401 & Ebert and Curry (1992) \\
\hline radiation transfer & & LW \& SW (rad) & 7 & CAR major radiation transfer schemes (Table 1) \\
\hline \multicolumn{3}{|c|}{ total number of experiments } & 448 & each for LW and SW \\
\hline
\end{tabular}

their interactions with climate. This study selects a few representative diagnostic schemes, with and without PDF-based subgrid variability, to depict the effects of cloud cover prediction. As driven by the ERI-predicted cloud water mixing ratios, which were shown in good agreement with satellite estimates ( $\mathrm{Li}$ et al., 2008, 2012), they are considered to be a reasonable proxy of the current GCMs' states.

\subsection{CAR radiation transfer accuracy}

This experiment includes simulations of the seven major schemes of both shortwave (SW) and longwave (LW) radiation transfer as driven by the input data from the Continual Intercomparison of Radiation Codes (CIRC) (Oreopoulos et al., 2012). The CIRC Phase I includes five clear-sky conditions and two overcast liquid clouds (Table 1). Since gas concentrations, aerosol single-scattering properties, cloud water path and effective particle size, and surface albedo (unweighted spectral) are given as the CIRC standard and surface emissivity is set to 1.0, the only freedom is the choice for cloud liquid optical property. There exist five LW and eight SW cloud schemes to choose from CAR. In total, $105 \mathrm{LW}$ and $147 \mathrm{SW}$ runs were made. The outcomes are compared with the LBL reference results available from CIRC to evaluate accuracy of various radiation transfer schemes and discrepancy associated with cloud optical property parameterizations.

\subsection{CAR greenhouse gas forcing estimate}

This experiment includes simulations of the seven major SW and LW radiation schemes using their original cloud parameterizations for five idealized conditions. All assume the standard midlatitude summer atmospheric profile (MLS) with no aerosol, surface skin temperature of $294 \mathrm{~K}$, solar constant of $1367 \mathrm{Wm}^{-2}$, solar zenith angle of $53^{\circ}$, and surface albedo of 0.1 and emissivity of 1.0. In addition to a clearsky condition, four overcast cases are considered following Fu et al. (1997): high cloud (10-12 km) with ice water content (IWC) of $0.0048 \mathrm{gm}^{-3}$ and effective particle size (dei) of $41.5 \mu \mathrm{m}$, middle cloud $(4-5 \mathrm{~km})$ with liquid water content (LWC) of $0.28 \mathrm{gm}^{-3}$ and effective particle radius (rel) of $6.2 \mu \mathrm{m}$, low cloud (1-2 km) with LWC of $0.22 \mathrm{gm}^{-3}$ and rel of $5.89 \mu \mathrm{m}$, and all of the above clouds. The only freedom is GHG concentrations, which are specified by the latest IPCC RCPs. They include RCP2.6 (low), RCP4.5 (mediumlow), RCP6.0 (medium-high), and RCP8.5 (high) emission scenarios (Meinshausen et al., 2011). In total, 420 runs (7 radiation schemes $\times 5$ sky conditions $\times 4$ emission scenarios $\times 3$ time periods) were made for both SW and LW. The outcomes of instantaneous (without stratospheric adjustment) top-of-atmosphere (TOA) net flux changes from the preindustrial era (1765) to the present (2005) and future (2100) are compared to illustrate the estimate range of future $\mathrm{GHG}$ radiative forcing projections, depending on clouds. 


\subsection{CAR aerosol direct radiative effect range}

This experiment includes global simulations of the seven major SW radiation schemes along with 64 cloud schemes (four parameterizations each for cover fraction, droplet size, and optical property listed in Table 2) as driven by 6-hourly meteorological conditions during January and July 2004 from the ERA-Interim observational analysis (ERI) (see below for a data description). The geographic distributions of aerosols were derived from the MISR climatological average over the period 2000-2008 (Kahn et al., 2005, 2007). The MISR provides monthly mean data of Ångström exponent $(\alpha)$, total aerosol optical depth (AOD) and single-scattering albedo (SSA) for four wavelengths at 440 (blue), 552 (green), 680 (red), and $886 \mathrm{~nm}$. On the other hand, the radiation schemes consider two broad bands, visible (VIS) and near-infrared (NIR), whose boundary wavelengths vary widely. As a firstorder approximation, the broadband mean AOD is calculated by $\bar{\tau}=\int_{\lambda_{b}}^{\lambda_{e}} \tau_{r}\left(\lambda_{r} / \lambda\right)^{\alpha} s_{\lambda} \mathrm{d} \lambda / \int_{\lambda_{b}^{\prime}}^{\lambda_{e}^{\prime}} s_{\lambda} \mathrm{d} \lambda$, where $s_{\lambda}$ is the insolation at wavelength $\lambda$ bounded by subscripts $b$ and $e$, and subscript $b$ and $e$, and subscript $r$ denotes for the reference MISR data within that band. This study defines the common

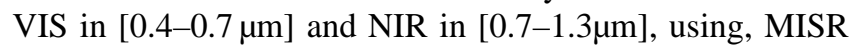
552 and $886 \mathrm{~nm}$ for the reference data, respectively. Superscript ' depicts the actual bounds in a specific scheme that may differ from the common windows. This simple scaling ensures that all schemes use the same AOD for each broadband, albeit with different bounds. The corresponding SSA for VIS results from a similar insolation-weighted spectral integration of monochromatic values that fits a second-order Lagrangian polynomial with MISR blue, green, and red data. The SSA for NIR adopts the MISR $886 \mathrm{~nm}$ data directly. In addition, the aerosol asymmetry factor, for which MISR has no data, is taken from MODIS (Chu et al., 2002; Remer et al., 2002). The outcomes of these runs (in total 448 pairs) with and without aerosols are compared to estimate the aerosol direct radiative effect and model diversity by using alternate radiation and cloud schemes. An additional eight runs are done to show the result sensitivities to the aerosol optical property parameterization and the semidirect effect of black carbon alone.

\subsection{CAR cloud radiative forcing distribution}

This experiment includes global simulations of the seven major SW and LW radiation schemes each combining with the 64 cloud schemes listed in Table 2 as driven by 6-hourly ERI meteorological conditions during January and July 2004. The aerosol direct effect is incorporated as described above. In total, 448 runs were made for both LW and SW. The outcomes are compared to quantify the cloud radiative forcing and discrepancy among the selected alternate cloud and radiation schemes. Here cloud vertical overlap treatment adopts the original scheme (McICA) for the cccma, gfdl, and rrtmg radiation packages, and the mixed (maximum/random) assumption of homogenous clouds for others. An additional 35 runs, combining an identical set of cloud parameterizations for cover fraction, water path, droplet size, and optical property with five geometry treatments and the seven major radiation schemes (Table 3), demonstrate the dominant effect of subgrid cloud variability on the spread of cloud radiative forcing calculations.

\subsection{CWRF/CAR regional climate impact}

This experiment includes regional climate simulations of the fully coupled CWRF/CAR over the extended US domain at $30 \mathrm{~km}$ grid spacing (Liang et al., 2012) as driven by lateral boundary conditions from the ERI data. For each of the seven major radiation packages with their original cloud configurations, CWRF was integrated continuously from 1 December 2003 to 31 December 2004, using the initial month as a model spin-up. The aerosol direct effect is also incorporated as described above. The outcomes are compared to determine the regional climate impact of cloud-aerosol-radiation interactions and the sensitivity that results from different formulations among the major radiation packages most commonly used in recent GCMs.

\subsection{Observational data and uncertainty}

The last three experiments require input from the ERI (Uppala et al., 2008), which contains 6-hourly data at $1.5^{\circ}$ grid spacing over the globe. In particular, the standalone CAR experiments (direct aerosol effect and cloud radiative forcing) use the following: (1) the cloud liquid and ice mixing ratio profiles to compute cloud water path; (2) the convective rainfall amount and base/top levels to diagnose convective cloud cover fraction; (3) the temperature and humidity profiles to determine stratiform cloud cover fraction; (4) the surface elevation, albedo, skin and air temperatures, and land mask to form the lower boundary conditions. The coupled CWRF/CAR experiment derives its lateral boundary conditions of temperature, humidity, wind, and height from ERI.

For the last two experiments, cloud quantities are evaluated against satellite products from ISCCP (Rossow et al., 1996), MISR (Di Girolamo et al., 1995), and CERES/ISCCPlike Aqua FM4 and Terra FM1 (Wielicki et al., 1996), while radiative fluxes are compared with those of SRB (Stackhouse et al., 2001; Cox et al., 2004), ISCCP D2 (Zhang et al., 2004), and CERES Aqua FM3, Aqua FM4, Terra FM1, Terra FM2, and EBAF (Wielicki et al., 1996). The differences among these satellite data form the range of observational uncertainties. To depict the climatic effects, surface $(2 \mathrm{~m})$ air temperature and precipitation over the contiguous US domain are assessed against the best available observational analysis from dense station measurements (see details in Liang et al., 2012). 
Table 3. The experiment design for cloud vertical overlap effect.

\begin{tabular}{|c|c|c|c|c|}
\hline \multicolumn{3}{|c|}{ Cloud/radiation components } & \multicolumn{2}{|c|}{ Scheme selected } \\
\hline \multirow{5}{*}{\multicolumn{2}{|c|}{ cloud cover fraction }} & stratiform (ccs) & 1 & Xu and Randall (1996) \\
\hline & & cirrus (cci) & 2 & Slingo (1987) \\
\hline & & boundary (cbl) & 1 & Slingo (1987) \\
\hline & & deep cumulus (ccb) & 3 & Slingo (1987) \\
\hline & & total (ctot) & 1 & based on ccs,cci,cbl,ccb \\
\hline \multicolumn{2}{|l|}{ cloud water path (cwp) } & & 2 & based on inputted cloud water mass mixing ratio \\
\hline \multirow{2}{*}{\multicolumn{2}{|c|}{ cloud droplet size }} & liquid (rel) & 1 & Savijärvi et al. (1997) \\
\hline & & ice (dei) & 1 & Kiehl et al. (1996) \\
\hline \multirow{6}{*}{\multicolumn{2}{|c|}{ cloud geometry }} & & 0 & original scheme of each radiation transfer package \\
\hline & & & 1 & Mosaic (Liang and Wang, 1997) \\
\hline & & & 2 & $\begin{array}{l}\text { McICA (Barker et al., 2002; Pincus et al., 2003; } \\
\text { Räisänen et al., 2004) with the following random } \\
\text { cloud generators: }\end{array}$ \\
\hline & & & & $\begin{array}{l}1 \text { Based on Räisänen et al. (2004) with } \\
\text { modification by M.J. Iacono }\end{array}$ \\
\hline & & & & $\begin{array}{l}2 \text { Based on total water following a symmetric } \\
\text { beta distribution }\end{array}$ \\
\hline & & & & $\begin{array}{l}3 \text { Based on Räisänen et al. (2004) with } \\
\text { modification by Jason Cole }\end{array}$ \\
\hline \multirow[t]{4}{*}{ cloud optical property } & LW & liquid (lwl) & 2 & Chou et al. (2001) \\
\hline & & ice (lwi) & 106 & Fu et al. (1998) \\
\hline & SW & liquid (swl) & 6 & Chou and Suarez (1999) \\
\hline & & ice (swi) & 106 & Fu et al. (1998) \\
\hline radiation transfer & & LW \& SW (rad) & 7 & CAR major radiation transfer schemes (Table 1 ) \\
\hline \multicolumn{3}{|c|}{ total number of experiments } & 35 & each for LW and SW \\
\hline
\end{tabular}

Table 4. Percentage differences of SWDNS from LBL reference calculations (LBLRTM for LW and CHARTS for SW) among CAR's major radiation schemes by eight cloud optical property schemes for CIRC Phase I case 6 and 7. For each radiation scheme, the smallest error among all cloud schemes is in bold, while the result from the original combination is in parentheses.

\begin{tabular}{lrrrrrrr}
\hline Radiation codes & $\mathrm{gsfc}$ & $\mathrm{cccma}$ & $\mathrm{cam}$ & $\mathrm{flg}$ & $\mathrm{gfdl}$ & $\mathrm{rrtmg}$ & cawcr \\
\hline \multicolumn{2}{c}{ case 6 (thick cloud, cwp $=263.4 \mathrm{~g} \mathrm{~m}^{-2}, \mathrm{LBL}=92.11 \mathrm{~W} \mathrm{~m}^{-2}$ ) } & & & \\
\hline swl1 & -11.71 & -12.45 & -10.53 & $(-7.50)$ & -17.68 & -8.25 & -13.97 \\
swl2 & $(-1.90)$ & -2.42 & -0.65 & -2.88 & -8.58 & $\mathbf{0 . 6 7}$ & -5.67 \\
swl3 & -12.74 & $(-12.49)$ & -10.35 & -7.13 & -18.06 & -8.82 & -14.99 \\
swl4 & $-\mathbf{0 . 8 8}$ & $-\mathbf{2 . 3 5}$ & $-\mathbf{0 . 5 6}$ & 2.72 & $-\mathbf{7 . 1 2}$ & $(2.02)$ & $(-\mathbf{2 . 1 2})$ \\
swl5 & -4.54 & -4.85 & $(-2.87)$ & $\mathbf{0 . 5 3}$ & -10.89 & -0.87 & -7.61 \\
swl6 & $(-1.90)$ & -2.42 & -0.65 & -2.88 & -8.58 & $\mathbf{0 . 6 7}$ & -5.67 \\
swl7 & -6.18 & -5.95 & -3.86 & -3.63 & $(-10.63)$ & -3.17 & -6.65 \\
swl8 & -15.37 & -15.44 & -13.45 & -13.77 & -19.61 & -14.00 & -15.65 \\
\hline case 7 (thin cloud, cwp $=39.1$ & $\left.\mathrm{~g} \mathrm{~m}^{-2}, \mathrm{LBL}=473.69 \mathrm{~W} \mathrm{~m}^{-2}\right)$ & & & \\
\hline swl1 & 1.01 & -3.34 & -3.48 & $(-3.85)$ & -4.50 & -3.27 & -5.03 \\
swl2 & $(5.78)$ & $\mathbf{1 . 6 2}$ & $\mathbf{1 . 3 7}$ & $\mathbf{0 . 9 6}$ & $\mathbf{0 . 3 7}$ & $\mathbf{1 . 5 5}$ & $-\mathbf{0 . 6 1}$ \\
swl3 & $\mathbf{0 . 2 5}$ & $(-4.03)$ & -4.22 & -4.02 & -5.13 & -3.65 & -5.99 \\
swl4 & 6.55 & 2.38 & 2.23 & 1.20 & 1.26 & $(1.90)$ & $(0.73)$ \\
swl5 & 2.28 & -1.83 & $(-2.00)$ & -2.16 & -3.03 & -1.56 & -3.76 \\
swl6 & $(5.78)$ & $\mathbf{1 . 6 2}$ & $\mathbf{1 . 3 7}$ & $\mathbf{0 . 9 6}$ & $\mathbf{0 . 3 7}$ & $\mathbf{1 . 5 5}$ & $-\mathbf{0 . 6 1}$ \\
swl7 & 1.55 & -2.75 & -2.93 & -3.43 & $(-3.72)$ & -2.86 & -3.79 \\
swl8 & -0.93 & -5.26 & -5.44 & -5.50 & -6.55 & -5.66 & -6.29 \\
\hline
\end{tabular}



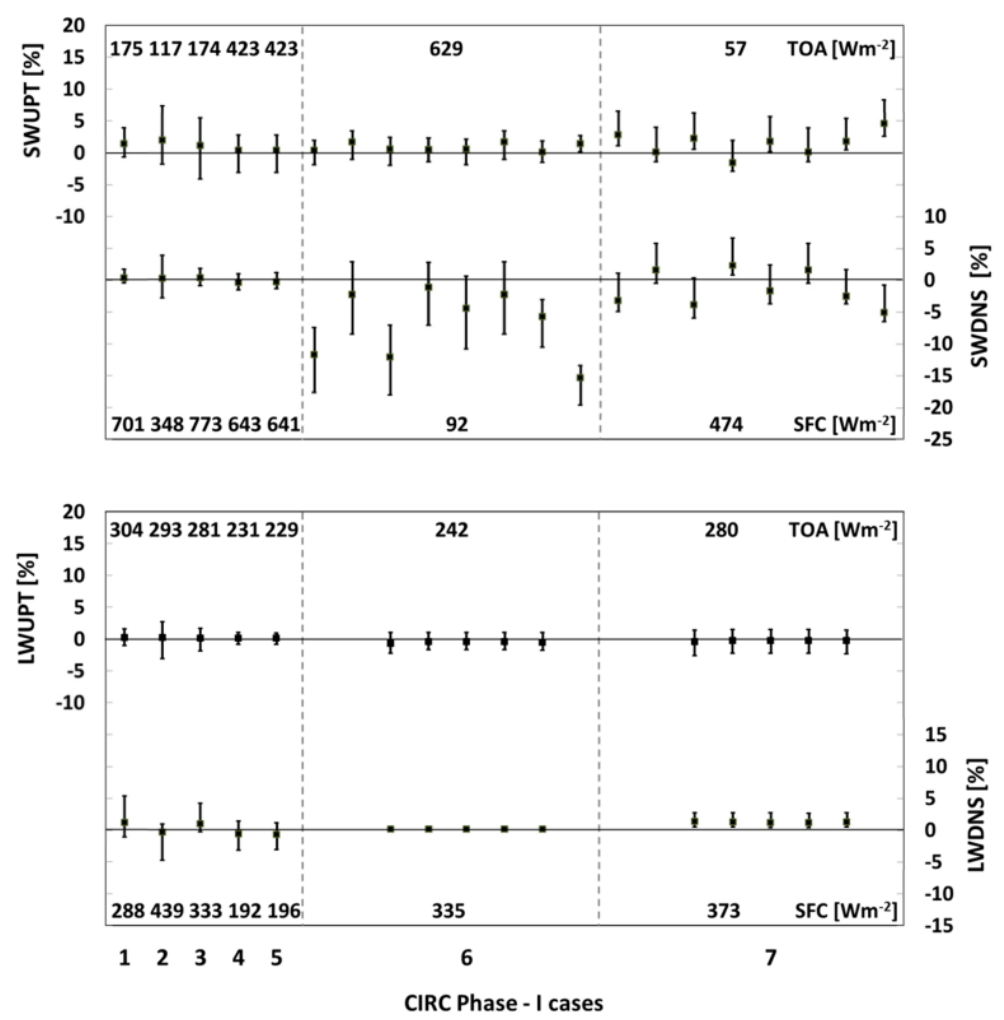

Fig. 2. The percentage differences (\%) from the LBL reference (LW: LBLRTM, SW; LBLRTM-CHARTS) among the seven major radiation transfer schemes, including their mean (block) and min-max range (error bar). For CIRC Phase I case 6 and 7, the results for five LW and eight SW cloud optical property schemes are shown. The reference values are listed in each panel at the top for TOA and the bottom for SFC, with the corresponding scaling at the upper left and lower right.

\section{CAR performance and result spread attribution}

Below presented are the CAR results of the five experiments in the sequential order as listed in Sect. 3. The presentation elaborates the CAR capability in modeling cloud, aerosol, and radiation variations, and their climate effects as coupled with CWRF, as well as attributing the result discrepancies to specific key components of the system.

\subsection{CAR radiation transfer accuracy}

Figure 2 compares the CAR outcomes among the seven major radiation schemes for each CIRC Phase I case, including their mean and min-max range of percentage biases from the LBL reference (LW: LBLRTM, SW; LBLRTM-CHARTS). For the overcast cases 6 and 7, the statistics are given separately for five $\mathrm{LW}$ and eight $\mathrm{SW}$ cloud liquid optical property schemes. Clearly the CAR overall accuracy is excellent, where the mean biases for all cases at the surface and TOA are within $\pm 1 \%$ for $\mathrm{LW}$ and -15 to $+5 \%$ for SW. The spread among different radiation transfer schemes, however, is nontrivial as their min-max ranges are generally larger. Under clear-sky conditions, discrepancies of $\pm 5 \%$ are identified with the treatment of water vapor absorption in both
LW and SW, as shown in the comparison of case 2 (moist) versus case 4 or 5 (very dry). Clouds reduce SW fluxes reaching the surface, with only $92 \mathrm{Wm}^{-2}$ in case 6 (thick overcast). As a result, the percentage min-max range across the radiation transfer schemes increases from $3 \%$ in clear cases to $10 \%$ under the thick cloud, although the corresponding absolute flux spread does not change much, from 20 to $21-$ $25 \mathrm{Wm}^{-2}$. Hence different treatments of water vapor absorption dominate the spread in calculating radiative fluxes under clear conditions and also overcast clouds in respect to any given scheme for their optical properties.

Note that surface SW fluxes differ largely between the seven radiation transfer schemes and between the cloud optical property schemes, with a range of $11.5-14.1 \%$ $\left(\sim 10-13 \mathrm{Wm}^{-2}\right)$ for the thick cloud and $6.4-7.4 \%(\sim 30$ $35 \mathrm{Wm}^{-2}$ ) for the thin cloud. Table 4 compares their percentage differences from the LBL reference among various combinations of radiation and cloud schemes for both overcast cases. Obviously, smallest errors are generally not identified with the default combination of the radiation transfer and cloud optical property schemes in the original packages, except for gfdl and rrtmg (thick cloud) and cawcr (both clouds). For example, in the thick cloud case, scheme 4 (Hu and Stanmes, 1993, with look-up tables), 8 (Hu and Stanmes, 1993), 

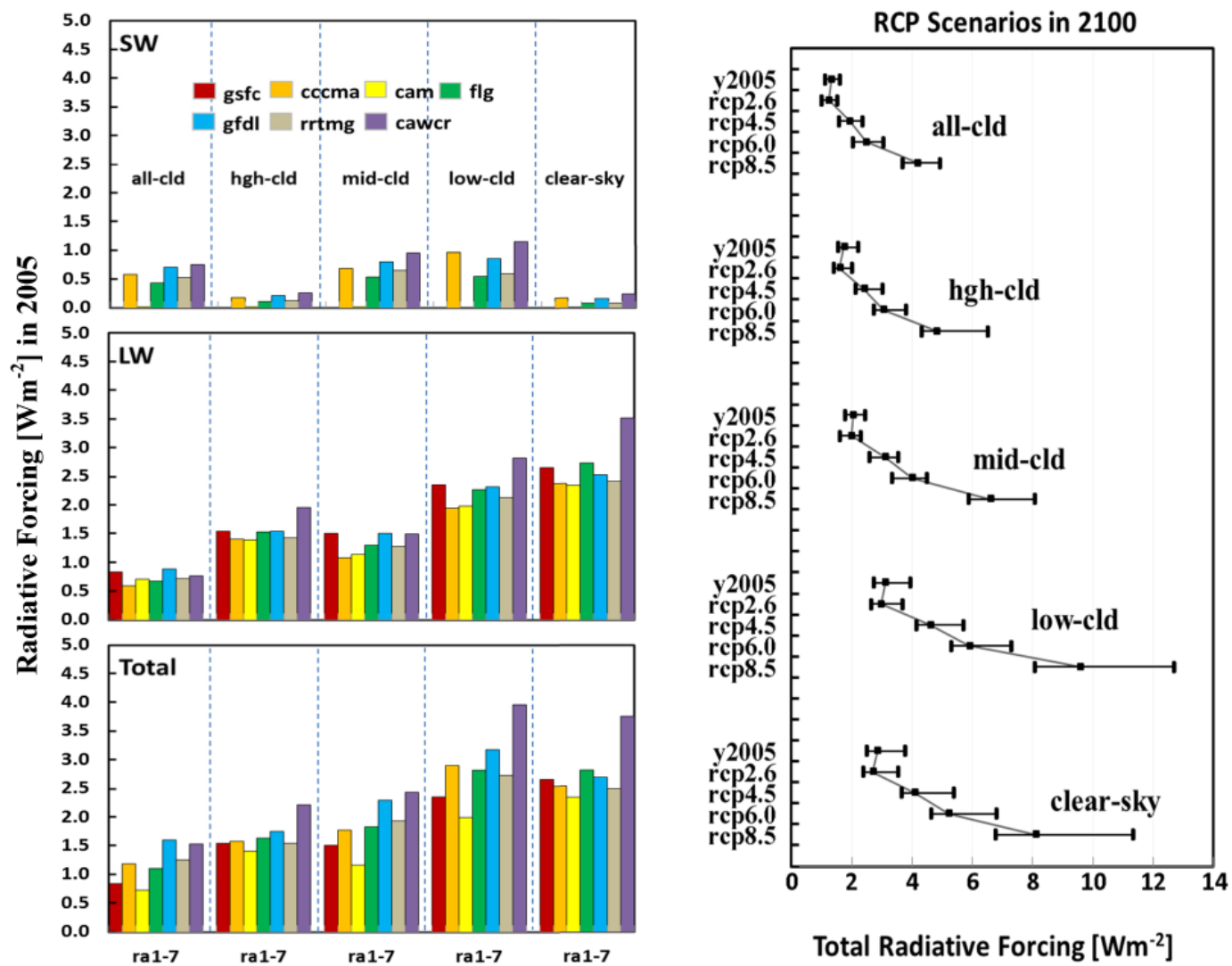

Fig. 3. The SW, LW, and total radiative forcings $\left(\mathrm{Wm}^{-2}\right)$ for the present condition in year 2005 among the seven major radiation transfer schemes (left), and the total radiative forcings $\left(\mathrm{Wm}^{-2}\right)$ under the clear-sky and prescribed low-, middle-, high-, and all-cloud conditions for the four IPCC RCP scenarios in year 2100 and present conditions (right). Error bars depict the min-max ranges among the radiation transfer schemes excluding gsfc and cam. These forcings are the instantaneous changes in TOA radiative fluxes relative to the aerosol-free condition in $1765 \mathrm{AD}$ without stratospheric adjustment.

and 2 (Chou and Suarez, 1999) are the best choices for gsfc, cccma, cam, and flg radiation transfer, respectively, reducing errors of the original cloud scheme by $2-8 \%$. In addition, no single cloud optical property scheme works best with all radiation transfer schemes. For example, scheme 4 combining with gsfc is the best for the thick cloud, but the worst for the thin cloud. The result indicates that the existing radiation packages have large room for improvement by optimal combinations of radiation transfer with cloud property schemes.

\subsection{CAR greenhouse gas forcing estimate}

Figure 3 compares the CAR outcomes among the seven major radiation schemes for the GHG radiative forcing under each of the four IPCC RCP scenarios, including their mean and min-max range of TOA net SW, LW, and total flux change from the preindustrial condition. As the GHG concentration increases from the present to future and from low to high emission scenarios, the mean radiative forcing increases. For all clear and cloudy cases, the LW forcing dominates, while the SW effect is only one-third or less. The total forcing, as averaged among all radiation schemes, is scalable, where the normalized flux changes relative to their respective $\mathrm{RCP}$ base (e.g., the ratio of the flux change to $4.5 \mathrm{Wm}^{-2}$ for RCP4.5) differ little between the four scenarios for all clear and cloudy cases. This indicates that the ensemble average over all radiation transfer schemes mainly depends on GHG concentrations under given cloud conditions.

On the other hand, the min-max range is less scalable. This range, or uncertainty due mainly to the treatment of gas absorption differing among the radiation transfer schemes, becomes larger as the GHG concentration increases. The normalized uncertainty of total radiative flux changes is systematically larger under RCP8.5 than RCP4.5 by a factor of 1.04 to 1.11 depending on clear and cloudy conditions in the year 2100. This indicates that future projection of the GHG radiative forcing and hence its climate consequence has a greater diversity for a higher emission scenario. Note that gsfc and cam schemes largely underestimate the roles of $\mathrm{CO}_{2}$ and $\mathrm{O}_{2}$ absorption in the near-infrared spectra, giving near-zero SW TOA forcing. Thus, the results from these two schemes are 
excluded in the analysis below on the average and spread of SW and total GHG radiative forcing.

Clouds have large effects on GHG radiative forcing. For RCP8.5 in the year 2100, the total forcing averaged over all five radiation transfer schemes is $8.11,9.57,6.60,4.82$, and $4.19 \mathrm{Wm}^{-2}$ for clear-sky and overcast conditions of low, middle, high, and all clouds, respectively. The differences result from contrasts in cloud altitude, thickness, and composition. Clouds, most effectively those at high altitudes, where temperatures are much colder than at the surface, reduce outgoing LW emission and hence total GHG radiative forcing. An exception is for optically thick low clouds, which produce larger GHG forcing than clear sky as they reflect more SW (for more gaseous absorption in the air above) but emit the same LW relative to the surface. The result of all clouds is close to that of high clouds because of the dominance by the LW forcing.

Clouds also alter the spread in GHG radiative forcing calculation. For RCP8.5 in the year 2100, the min-max range of the SW forcing across the five radiation transfer schemes is small $\left(0.5 \mathrm{Wm}^{-2}\right)$ for both clear sky and high cloud (optically thin), while increased to $1.23,2.26$, and $1.08 \mathrm{Wm}^{-2}$, respectively for middle, low, and all clouds. Low clouds produce the largest SW forcing inter-model discrepancies as they are optically thick. In contrast, the LW forcing is determined by vertical differentiation in emitter temperature and absorber optical property. As such, the LW spread is largest $\left(4.27 \mathrm{Wm}^{-2}\right)$ for clear sky, while reduced to $2.03,1.51,2.88$ and $0.61 \mathrm{Wm}^{-2}$ for high, middle, low, and all clouds, respectively. (The corresponding values when including gsfc and cam are 4.37, 2.07, 1.68, 3.22, and $0.61 \mathrm{Wm}^{-2}$, respectively.) Given the dominance of LW effects, clouds tend to decrease the total GHG radiative forcing diversity. One exception, as discussed above, is for low clouds, which produce a slightly larger total forcing spread than clear sky (4.62 vs. $4.55 \mathrm{Wm}^{-2}$ ).

\subsection{CAR aerosol direct radiative effect range}

Figure 4 compares the CAR outcomes among the seven major radiation schemes for the globally averaged total (natural and anthropogenic) aerosol direct effects on SW net radiative fluxes and CRFs at TOA and surface under clear-sky and all-sky conditions among the 64 cloud schemes listed in Table 2, each including its mean and min-max range across the seven major radiation transfer schemes. The median and the 25 th and 75 th percentiles are also given for reference. Shown are the results for the mean of January and July 2004 using the MISR climatological monthly mean aerosol distributions. Clouds reduce aerosol direct effects on TOA and surface radiative fluxes, with their respective full-ensemble mean magnitudes decreased from 5.05 and $6.40 \mathrm{Wm}^{-2}$ in clear sky to 3.06 and $4.37 \mathrm{Wm}^{-2}$ in all sky. Such differences of -2.01 and $-2.03 \mathrm{Wm}^{-2}$ between clear sky and all sky represent the SW CRF changes (weakening in both TOA and surface) due to aerosol direct effects. The presence of aerosols, through changes in total optical properties, causes larger reflection in clear sky and more absorption in clouds, and thus results in a weaker CRF at both TOA and surface.

The above result is in general agreement with the existing estimates. The global ocean annual mean clear-sky aerosol direct radiative effect ranges from -3.8 to $-6.8 \mathrm{Wm}^{-2}$ based on satellite estimates, and from -1.6 to $-4.1 \mathrm{Wm}^{-2}$ based on model simulations (Yu et al., 2006; IPCC, 2007). The corresponding values in the mean of January and July of 2004 from our CAR ensemble, varying from -4.90 to $-5.49 \mathrm{Wm}^{-2}$, fall into the range of the satellite estimates, but are more negative than the model simulations. $\mathrm{Yu}$ et al. (2006) also used MISR (early version) AOD in combination with GOCART aerosol optical properties to give a global mean estimate of $-6.5 \mathrm{Wm}^{-2}$ over ocean and $-4.9 \mathrm{Wm}^{-2}$ over land. Our CAR ensemble mean estimate of $-5.2 \mathrm{Wm}^{-2}$ over ocean is less negative by $\sim 20 \%$, while that of $-4.1 \mathrm{Wm}^{-2}$ over land is very close. The large difference over ocean could be partly explained by an overall overestimate of $20 \%$ (Kahn et al., 2005) in early post-launch MISR AOD retrievals over ocean as used in Yu et al. (2006). Differences in aerosol optical properties and surface albedo between the two studies are among the other contributing factors.

The model outputs for global all-sky aerosol direct effects depend on radiation, cloud, and aerosol schemes. Different radiation schemes simulate aerosol effects, when averaged over the 64 cloud schemes, between negative 2.71-3.34 (4.19-4.62) $\mathrm{Wm}^{-2}$ for net SW fluxes and positive 1.60-2.37 (1.65-2.48) $\mathrm{Wm}^{-2}$ for CRF at TOA (surface). Thus the discrepancies for these variables due to the choice of radiation scheme are about $0.62(0.43)$ and $0.77(0.83) \mathrm{Wm}^{-2}$, respectively. The corresponding discrepancies due to the choice of cloud schemes, as depicted by the min-max ranges of individual radiation schemes, are 0.76-0.91 (0.82-0.99) and $0.76-0.91(0.82-0.99) \mathrm{Wm}^{-2}$, respectively. Therefore, the discrepancies that result from radiation and cloud schemes are comparable, and relative to the mean aerosol forcing itself, they are quite large, accounting for $20-30 \%$. These model spreads are likely underestimated since only a limited number of radiation and cloud schemes are selected here.

One may argue that the result is biased since not all combinations of the cloud and radiation schemes are actually applied in the current GCMs that require system tuning to maintain realistic energy balance in order to prevent climate draft. The general constraint for such tuning is the model climatological mean total radiative balance at TOA that should be close to observations. The observational uncertainty may be defined as the range across the estimates from ISCCP, SRB, CERES, and CERES_EBAF. In January (July) 2004, these estimates range from 261.28 to 273.91 (247.75 to 257.00$) \mathrm{Wm}^{-2}$ for net $\mathrm{SW}$, negative 239.01 to 242.94 (246.64 to 250.63 ) $\mathrm{Wm}^{-2}$ for net $\mathrm{LW}$, and 22.27 to 32.42 (1.11 to 8.29) $\mathrm{Wm}^{-2}$ for net total radiative flux. Note that the 

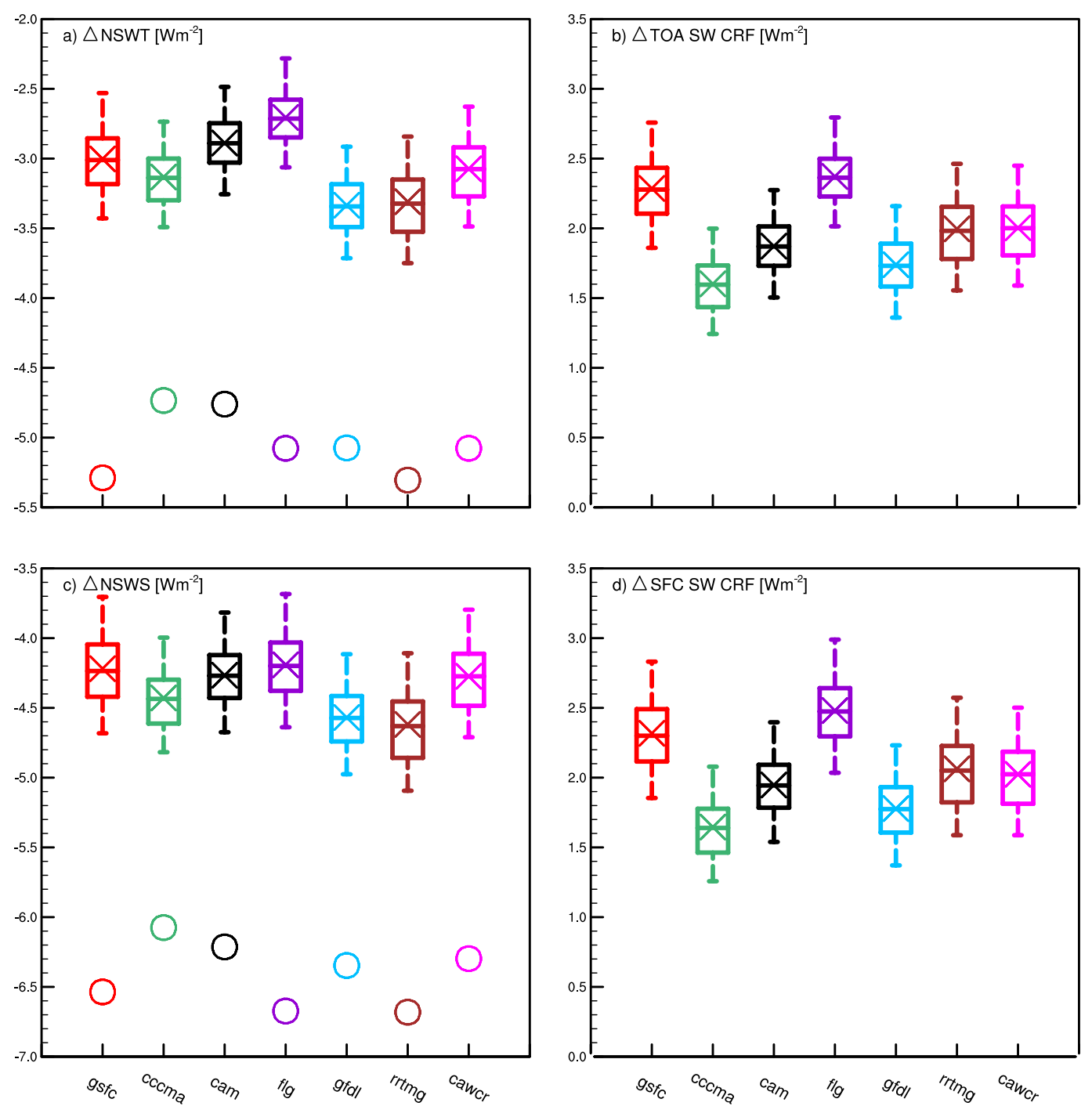

Fig. 4. Global mean aerosol direct radiative effects on TOA (top) and surface (bottom) SW all-sky net fluxes with clear-sky values (circle, a, c) and CRFs (b, d) on average for January and July 2004 using the MISR climatological aerosol distribution. The box plot shows the minimum, 25th percentile, median, 75th percentile, and maximum values among the 64 cloud members for each radiation transfer scheme, while the $\mathrm{X}$ within each box depicts the ensemble mean.

values are averaged over $60^{\circ} \mathrm{S}-60^{\circ} \mathrm{N}$ to avoid poor quality satellite data over high latitudes. Among the total 1792 realizations ( 8 cloud physical properties $\times 4 \mathrm{SW} \times 4 \mathrm{LW}$ cloud optical properties $\times 7$ radiation transfer schemes), about $491(\sim 27 \%)$ configurations produce both January and July net total radiative fluxes within the observational uncertainty range. On average for January and July 2004, this subset of the constrained configurations gives an averaged global mean aerosol direct effect of $-5.02(-6.37) \mathrm{Wm}^{-2}$ for clear sky and $-3.10(-4.40) \mathrm{Wm}^{-2}$ for all sky at TOA (surface). Their standard deviations among individual configurations are 0.45 (0.40) and $0.34(0.30) \mathrm{Wm}^{-2}$, respectively. The corresponding values from the rest configurations outside of the observational range are $-5.06(-6.42)$ and $-3.05(-4.36$ for the mean and $0.46(0.41)$ and $0.37(0.32) \mathrm{Wm}^{-2}$ for the deviation. The differences between the two subsets are small, indicating that the CAR ensemble estimate of the aerosol direct effect changes little whether the TOA radiative balance is constrained toward observations or not.

An additional four runs are made to illustrate the sensitivity to the choice of the parameterization schemes for aerosol optical properties. Here the 3-D distributions of sulfate, sea salt (fine, coarse), dust (four sizes), and carbon (four types) aerosols are adopted from the present-day reference designated for the CMIP5 assessment (Taylor et al., 2009). Given the same grid-mean cloud cover fractions diagnosed from ERI and identical cloud optical properties from the original cccma package, two radiation codes (cccma and 

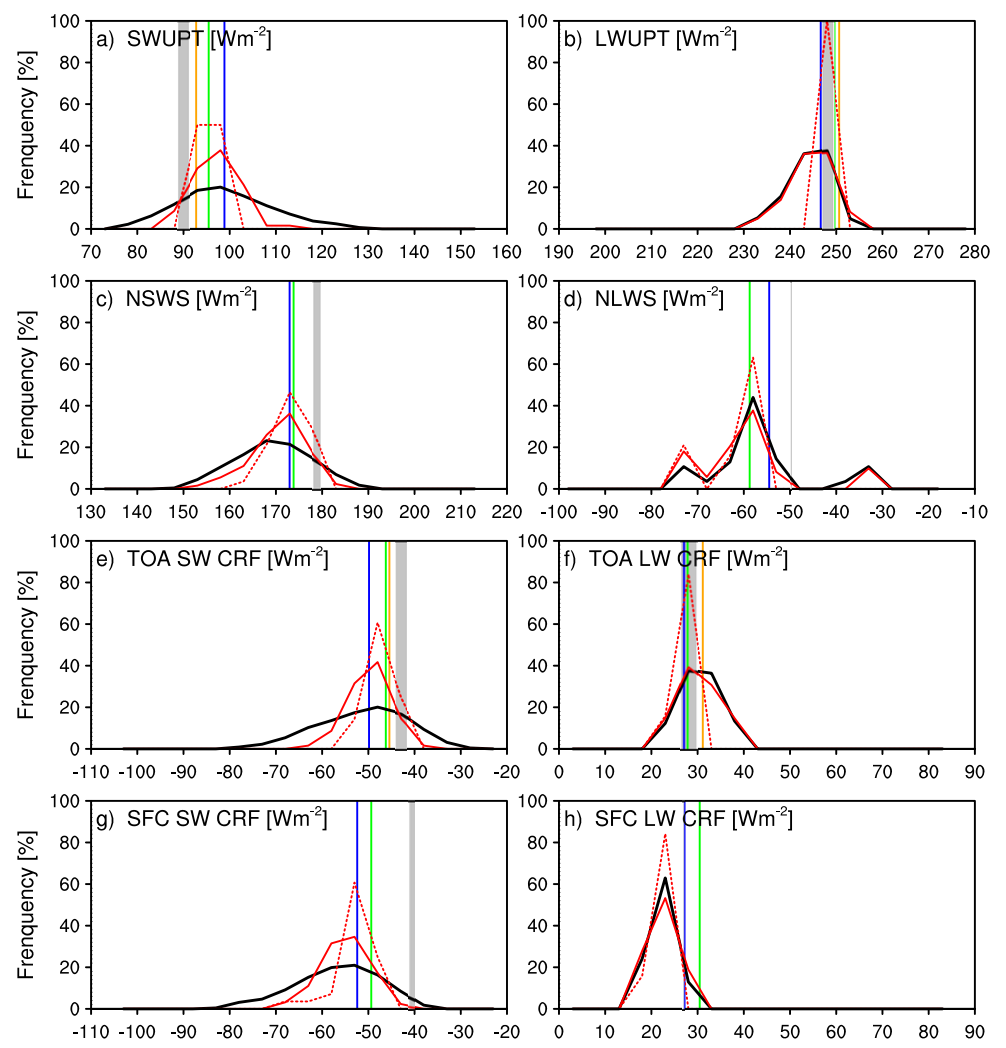

Fig. 5. The CAR member frequency distributions (thick black curves) in predicting the top and surface net radiative fluxes (a-d), $\mathrm{Wm}^{-2}$ ) and cloud radiative forcings (CRF, $(\mathrm{e}-\mathrm{g}), \mathrm{Wm}^{-2}$ ) averaged over $\left[60^{\circ} \mathrm{S}-60^{\circ} \mathrm{N}\right]$ in July 2004 for SW (left) and $\mathrm{LW}$ (right) to a subset of 448 members. The red curves are the respective results from the subset with the observational constraints on NSWT and NLWT separately (dashed) and their sum (solid). The CAR ensemble mean (black) is compared with the observational data from ISCCP (red), SRB (green), various versions of CERES (purple shading), and CERES_EBAF (orange).

flg) including their own radiative transfer and subgrid cloud structure treatment are compared in combination of the two parameterization schemes for the aerosol optical properties: the cccma set (Li et al., 2001; Li and Min, 2002); and the OPAC set (Hess et al., 1998). They are selected to depict the first-order sensitivity range based on a 1-D test. When the cccma optical properties are adopted, the global mean aerosol effects on average for January and July 2004 at TOA (surface) that resulted from the cccma and flg codes are respectively negative $9.78(11.81)$ and $9.14(11.34) \mathrm{Wm}^{-2}$ for net SW flux, and positive 4.89 (4.55) and $6.97(6.92) \mathrm{Wm}^{-2}$ for CRF. The result changes substantially when using the OPAC optical properties, which simulate the respective aerosol effects as negative $3.22(7.34)$ and $2.04(6.31) \mathrm{Wm}^{-2}$ for net SW flux, and positive $1.07(0.72)$ and $2.81(2.70) \mathrm{Wm}^{-2}$ for CRF. The two sets of aerosol optical properties generate large differences not only in TOA or surface fluxes but also in flux vertical differential distributions causing radiative heating rate contrasts. These differences are much larger than those due to the choices of the cloud and radiation schemes (as illustrated by the cccma versus flg codes), indicating the dominant role of the aerosol optical property representation in estimating aerosol direct effects.

Another set of four similar runs is conducted except including the extra SW absorption of black carbon within clouds as represented by the perturbation approach of $\mathrm{Li}$ et al. (2011). These offline runs exclude the feedback from cloud cover change induced by the absorption, and hence do not account for the actual semidirect effect. Concerned with here are only the flux changes due to internal mixture of black carbon within clouds, offering a reference for future investigation on aerosol semidirect effects in CAR-coupled climate models that predict cloud changes. On average for January and July 2004, the absorption effect for net SW flux at TOA (surface) is $1.98(-1.76)$ and $1.96(-1.67) \mathrm{Wm}^{-2}$ as resulted from the cccma and flg radiation, respectively, using the same cccma aerosol optical property scheme. The result changes little when using the OPAC property scheme, with the corresponding values of $2.01(-1.75)$ and 1.98 $(-1.66) \mathrm{Wm}^{-2}$. Therefore the estimate for the absorption, and likely the semidirect effect, of black carbon has little sensitivity to the choice for the radiation and aerosol optical property schemes. 


\subsection{CAR cloud radiative forcing distribution}

Figure 5 compares the frequency distributions for TOA and surface SW and LW radiative fluxes averaged over $60^{\circ} \mathrm{S}-$ $60^{\circ} \mathrm{N}$ (excluding polar regions to reduce surface ice or snow cover impacts on cloud identification and radiation retrieval) in July 2004 among 448 members combining the seven major radiation transfer schemes each with the 64 cloud schemes listed in Table 2. Clearly there exists a substantial spread among the members: $30-60 \mathrm{Wm}^{-2}$ varying in $\mathrm{LW}$ or SW all-sky fluxes at the TOA or surface. A similar discrepancy range can be found for cloud radiative forcing (CRF). This implies that the model result spread is caused mostly by the difference in CRF, which in turn is determined by the parameterization for cloud overlap, cover fraction, and optical property. The best available observational estimates also contain nontrivial uncertainties, ranging from 5 to $10 \mathrm{Wm}^{-2}$ for all-sky fluxes and 5 to $15 \mathrm{Wm}^{-2}$ for CRFs. Notably, the frequency peaks for all fluxes match more closely the ISCCP or SRB estimates, suggesting that the majority of the schemes used in the leading GCMs may have been tuned toward those data. Yet the recent satellite retrievals of CERES, except for its EBAF version, fall at the tails of the model distributions, especially for the net surface SW and LW all-sky fluxes and SW CRFs. It is not clear whether the discrepancies among the satellite estimates result from the differences in their retrieval algorithms that involve certain radiative transfer modeling. Similar findings apply for January 2004 (not shown).

The above result raises a serious concern as to whether the existing GCMs correctly represent the actual interactions between cloud, aerosol, and radiation. The large observational uncertainty and substantial model departure range suggest that these numerical representations are likely biased in a significant way. The frequency distributions are skewed from the observational bounds, indicating that the schemes chosen here are also insufficient in variety. Since the cloud and radiation schemes chosen in Table 2 have been used individually or as certain combinations in the current GCMs, they are representative of the state of the knowledge in cloud-radiation modeling. As discussed earlier, all GCMs must be tuned to maintain a realistic TOA radiative balance to contain model climate drifts. Thus not all combinations are practically applicable. Following the aerosol experiment above, only 491 of the 1792 configurations produce net total radiative fluxes within the observational uncertainty range averaged over the globe both in January and July 2004. The frequency distributions of the eight radiative fluxes from this constrained subset are also shown in Fig. 5. Excluding the $10 \%$ extremes, the SW CRF range (95th minus 5th percentile) among all combinations is $54(50) \mathrm{Wm}^{-2}$ at TOA (surface). This range is reduced to 32 (32) $\mathrm{Wm}^{-2}$ when constraining the net TOA flux within the observational range. No change occurs in the LW CRF range. These constrained CRF ranges are still over three times larger than the respective observational uncertainties, i.e., 8 (12) $\mathrm{Wm}^{-2}$ for $\mathrm{SW}$ and 5 (4) $\mathrm{Wm}^{-2}$ for $\mathrm{LW}$. A more strict constraint requiring both SW and LW fluxes at TOA to fall within the observational uncertainties further reduces the model ranges to 18 (27) and $14(14) \mathrm{Wm}^{-2}$, respectively. These values are approximately twice as large as the observational uncertainties.

Such an observational constraint exercise does not exclude any cloud or radiation component schemes listed in Table 2 , indicating that all these schemes are equally justifiable by observations. No single set of the cloud schemes is identified to produce the most realistic results across all radiation schemes. It is more general that different cloud schemes coupled with different radiation schemes produce the best match with observations. Therefore the tuning for the current GCMs to reproduce the observed radiative balance may not likely result from the correct physics at individual process levels, but rather from compensating errors among different components. We may have to accept the range of observational uncertainty from these best available data. The selection of the parameterization schemes, however, must be expanded to make the frequency distribution of the representative ensemble of CAR peak around that range. The unprecedented complete collection of alternate schemes in the CAR ensemble provides a unique opportunity to do so.

Figure 6 compares zonal mean total cloud cover fractions among four prediction schemes (Table 2) each with five vertical overlap assumptions (Table 3). Different (two convective + two stratiform) cloud cover schemes predict a notable result spread over midlatitudes, especially large $(\sim 0.1)$ in the Southern Hemisphere, where low-pressure and stratiform cloud systems prevail. Different cloud overlap assumptions generate an even larger result spread, ranging from 0.1 in the tropical deep convection zone to 0.2 in the southern midlatitudes. In general, the mixed overlap assuming a maximum/random vertical association between adjacent/nonadjacent cloud layers (ovp1) produces the smallest total cloud cover, the mixed overlap among high/middle/low bulk cloud layers (ovp2) gives the medium value, and the random overlap (ovp3) simulates the largest amount. CAR also incorporates the mosaic (ovp4) and McICA (ovp5) approaches, which divide a grid column into multiple cells to explicitly consider subgrid effects. As each subcell currently adopts ovp1, both mosaic and McICA result in zonal mean total cloud almost identical to those of ovp1 (not shown). As compared with observations, the ovp3 result is the most realistic for $30-65^{\circ} \mathrm{S}$ and $20-50^{\circ} \mathrm{N}$ in January and for $20-65^{\circ} \mathrm{S}$ and $35-50^{\circ} \mathrm{N}$ in July, whereas the ovp1 outcome is the worst, with large underestimation in these regions. On the other hand, all overlap treatments overestimate total cloud cover in the tropics by a large amount (0.2). This results mainly from larger cumulus cloud cover, which is currently parameterized in terms of convective rainfall (Slingo, 1987). Figure 6 illustrates an example of tuning that scheme with a smaller base fraction ( 0.1 vs. 0.245 for trace rainfall) to result in total cloud cover about 0.1 less than the observed. A credible 

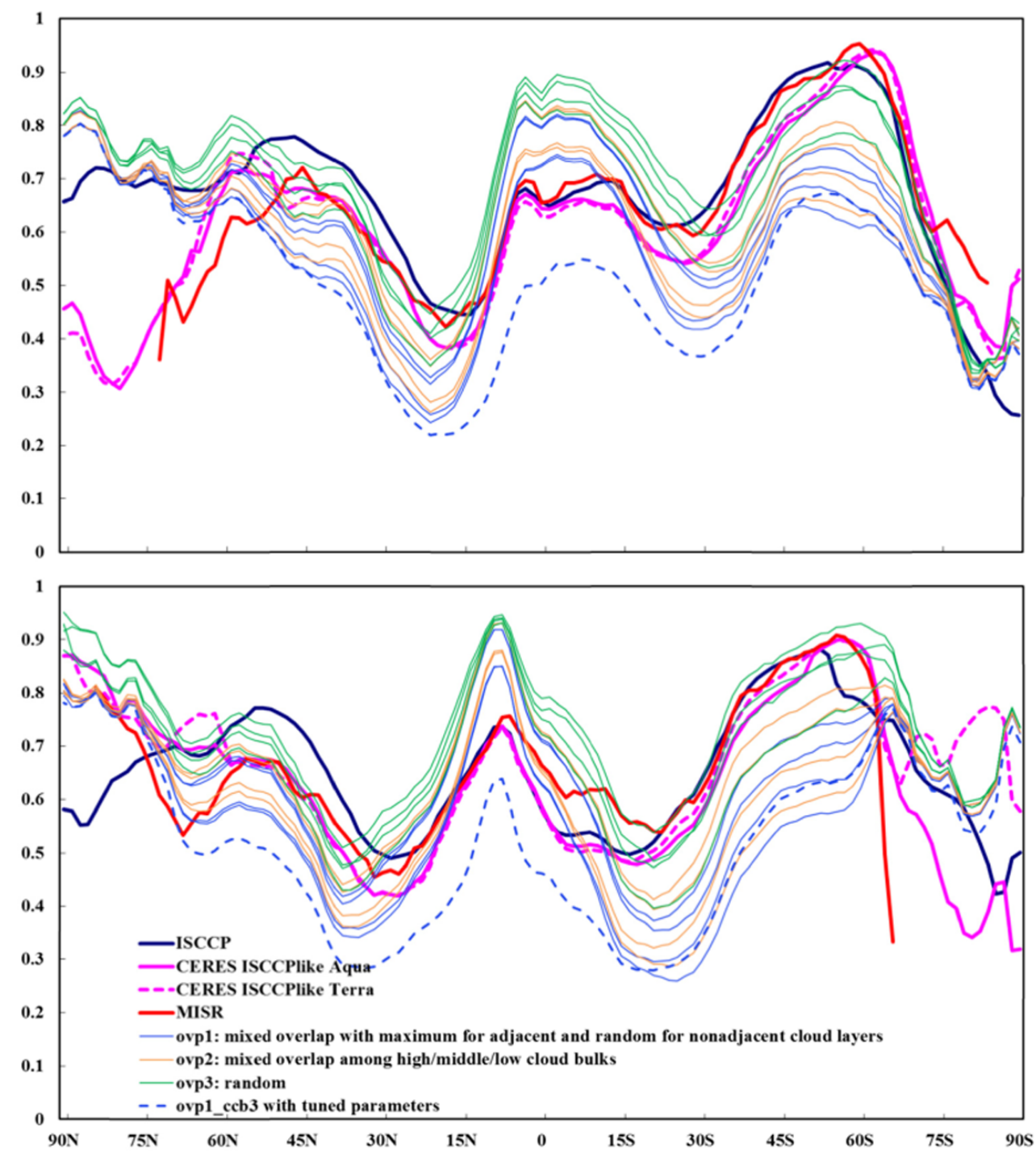

Fig. 6. Zonal mean total cloud cover fractions for January (top) and July (bottom) 2004 among three vertical overlap schemes built in CAR, as compared with four satellite products. For each overlap scheme, four cloud cover prediction schemes are shown using the same color.

tuning of such must be guided by high-quality observations, which are currently lacking.

Note that observational uncertainties are nontrivial, where the best available satellite products differ by $0.05-0.1$. Nonetheless, it is optimistic that fine tuning, or better selection from the CAR cloud ensemble, of the cloud cover prediction scheme along with overlap treatment can significantly improve the simulation of total cloud cover distribution. Particular advances can be made in the tropics by reducing convective cloud cover such as that parameterized in terms of convective updraft mass flux (Neale et al., 2010, which has been built into CAR but requires the interactive CWRF to provide input), as well as in the subtropics and midlatitudes by improving stratiform cloud cover prediction (Tompkins, 2002; Watanabe et al., 2009) and overlap treat- ment that depend on the prevailing climate regimes (Rossow et al., 2005; Naud et al., 2008).

Figure 7 compares CRF observations and simulations, with and without the observational constraint, by the seven major radiation transfer schemes, including their respective ensemble means and min-max ranges among the 64 cloud schemes listed in Table 2. The median and the 25th and 75th percentiles are also given for reference. Shown are averages over $60^{\circ} \mathrm{S}-60^{\circ} \mathrm{N}$ for both SW and LW at the TOA and surface in January and July 2004. Without the observational constraint, the result shows that the existing cloud-radiation schemes produce large errors, which are about $\pm 30 \mathrm{Wm}^{-2}$ in $\mathrm{SW} \pm 10 \mathrm{Wm}^{-2}$ for $\mathrm{LW}$, and also suggests that an ensemble approach is desirable to reduce overall model departures from observations. The original radiation packages 

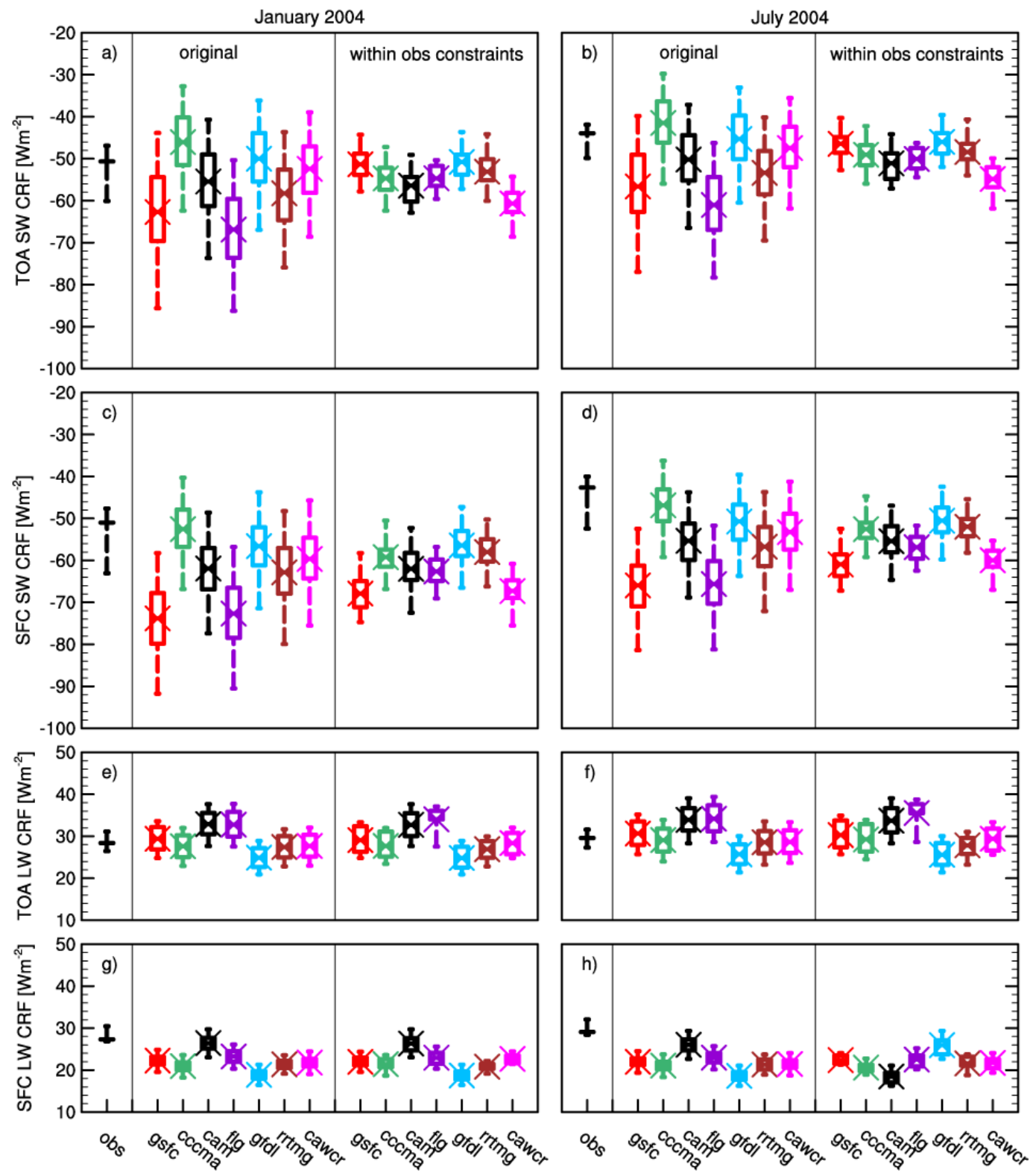

Fig. 7. The SW cloud radiative forcing (CRF) averaged over $\left[60^{\circ} \mathrm{S}-60^{\circ} \mathrm{N}\right]$ in January (left) and July (right) 2004. Shown are observations (min-max ranges among ISCCP, SRB, CERES, and CERES EBAF), the original results and those with the observational constraints on $($ NSWT + NLWT), respectively. The box plot illustrates the minimum, 25th percentile, median, 75th percentile, and maximum values among different cloud members for each radiation transfer scheme, while the $\mathrm{X}$ within the boxes depicts the ensemble mean.

gsfc, cccma, cam, flg, gfdl, rrtmg, and cawcr adopt cloud overlap assumptions $2,5,1,2,5,5$, and 1 , respectively. The min-max range for each radiation scheme depicts the discrepancy due to different cloud parameterizations for cover fraction, water path, droplet size, and optical property, while the spread among the seven radiation ensemble means is caused mainly by different treatments for cloud overlap. The min-max ranges for SW and LW due to cloud parameterizations are about $20-40$ and $10 \mathrm{Wm}^{-2}$, respectively, while the corresponding spreads caused by overlap treatments are about $20-25$ and $5-10 \mathrm{Wm}^{-2}$. The two effects are comparable in magnitude and quite large from the global perspective.

The observational constraint does reduce the model spread in simulating the TOA CRFs as it is supposed to. The total spreads in CRFs at TOA (surface) among all simulations are now 15 (29) $\mathrm{Wm}^{-2}$ for SW and 16 (14) $\mathrm{Wm}^{-2}$ for LW. These values, however, are still 2-3 times larger than the observational uncertainty ranges, i.e., $8(12) \mathrm{Wm}^{-2}$ for $\mathrm{SW}$ and 5 (4) $\mathrm{Wm}^{-2}$ for LW. Substantial differences also remain in the differential fluxes between TOA and surface, indicating that 

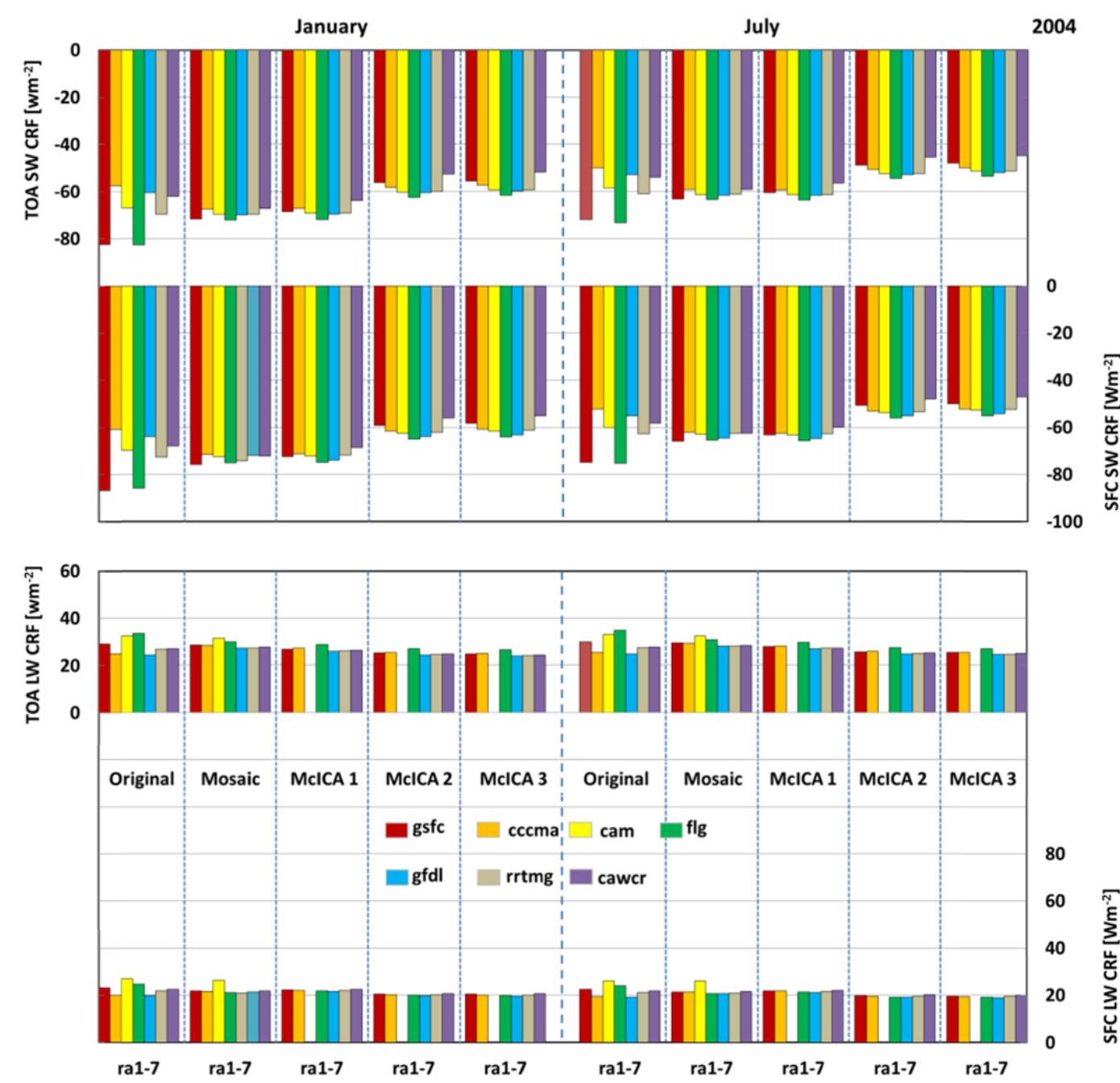

Fig. 8. The effects of cloud overlap treatment comparing the original scheme, mosaic, and McICA with three cloud generators on TOA and surface (SFC) SW and LW cloud radiative forcing (CRFs) averaged over $\left[60^{\circ} \mathrm{S}-60^{\circ} \mathrm{N}\right]$ for January (left) and July (right) 2004.

modeled atmospheric absorptions have important differences from observations.

To separate various cloud effects, Fig. 8 compares the results from five overlap treatments for each of the seven major radiation schemes, where cloud parameterizations for cover fraction, water path, droplet size and optical property are identical. These treatments include the original assumption (see above used in Fig. 7) and the mosaic approach as well as the McICA approach with three random generators (Table 3). Since the cam LW radiation transfer considers a single broadband, McICA is not effective and mosaic has little effect. Strikingly, the use of the mosaic or McICA approach essentially removes the CRF discrepancies among the radiation packages, where the SW differences are reduced from the original $20-25$ to less than $5 \mathrm{Wm}^{-2}$ by mosaic and to $5-10 \mathrm{Wm}^{-2}$ by McICA, and the LW differences from 510 to $1-3 \mathrm{Wm}^{-2}$ by both. The general implementation of the mosaic and McICA approaches into the CAR system fully decouples the determination of cloud structure information from radiation transfer calculations. This combines with the aforementioned cloud parameterizations to form the most comprehensive cloud driver that provides all physical, optical, and geometric cloud data consistently for all radiation transfer models to calculate both SW and LW fluxes and heating rates. As such, discrepancies among the models and from observations can be better understood and specifically attributed to various elements of the CAR cloud or radiation component (Zhang et al., 2013), and ultimately reduced by refining physical representations.

\subsection{CWRF/CAR regional climate impact}

Figure 9 compares, among the seven major radiation packages of the original configurations, monthly variations during 2004 of CWRF biases in surface net SW and LW radiative fluxes (NSWS, NLWS) and their CRFs, precipitation, 

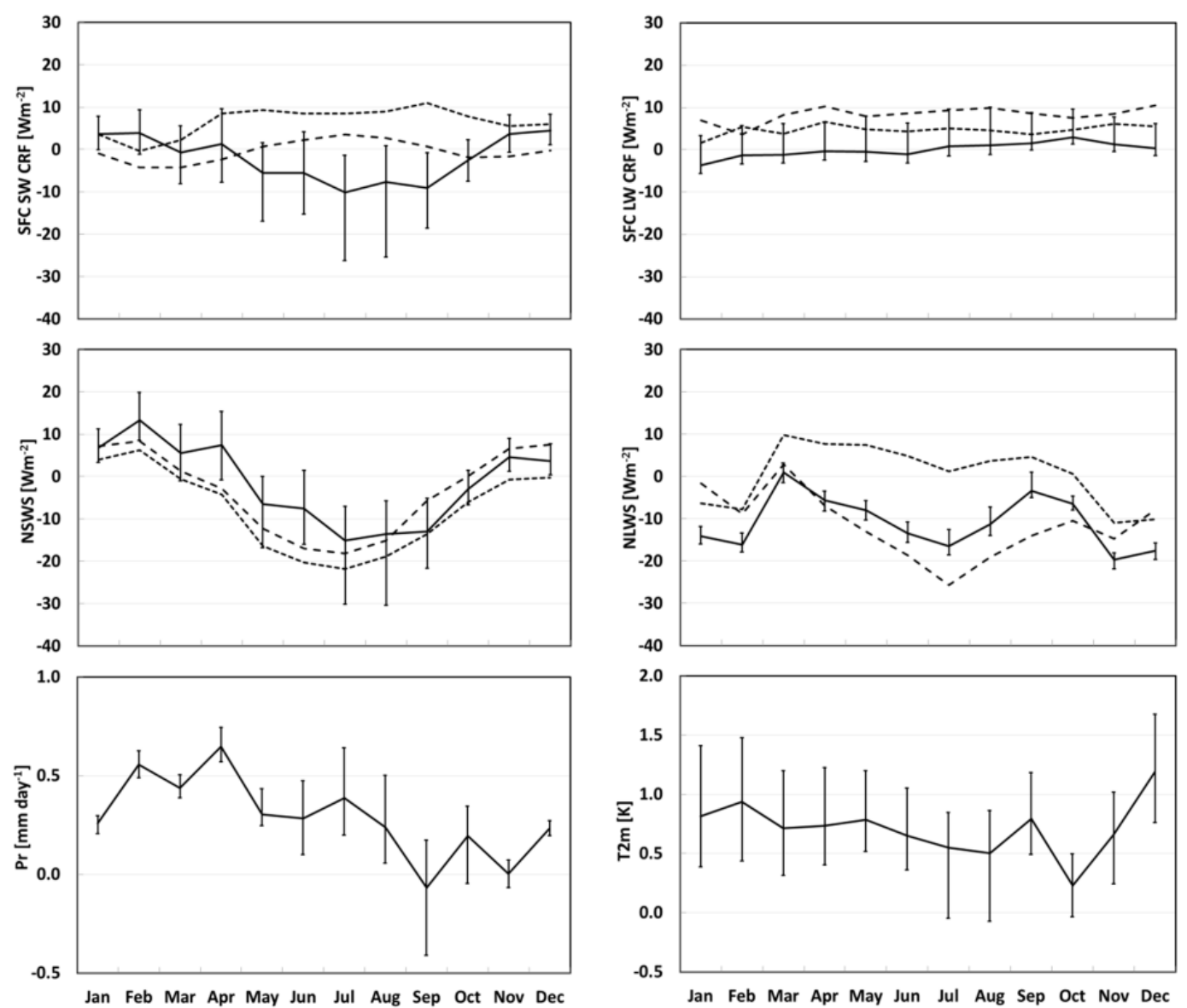

Fig. 9. Monthly variations during 2004 of CWRF biases averaged over the US land for surface net SW and LW radiative fluxes and the CRFs $\left(\mathrm{Wm}^{-2}\right)$, surface air temperature $(\mathrm{T} 2 \mathrm{~m}, \mathrm{~K})$, and precipitation $\left(\mathrm{Pr}, \mathrm{mm}_{\text {day }}{ }^{-1}\right)$, including the ensemble mean and min-max range among the seven major radiation packages. The reference for radiative quantities is from ISCCP, along with the observational uncertainty shown as the departures of SRB (dashed) and CERES (dotted).

and surface air temperature averaged over the US land. The reference for radiative quantities is from ISCCP, to which the SRB and CERES departures are also given as a measure of observational uncertainty. Both the ensemble mean and min-max range across the packages are presented. The result shows a strong seasonal cycle in the mean NSWS, with systematic underestimates of $10-25 \mathrm{Wm}^{-2}$ in summer due mainly to excessive CRFs, and overestimates of a smaller magnitude in winter. The min-max range exhibits a similar seasonality, about $20 \mathrm{Wm}^{-2}$ in summer and $10 \mathrm{Wm}^{-2}$ in winter. The observational uncertainty, however, is quite large, where SRB and CERES have systematic deficits from ISCCP, with peaks of $15-20 \mathrm{Wm}^{-2}$ in summer. As such, the ensemble mean falls within the observational bound. In contrast, the spread among the radiation packages can be greater than the bound, especially in summer. This is more clearly seen in comparison of spatial root-mean-square errors (rmse, not shown), which are greater in CWRF than those of SRB and CERES throughout the year. For LW, the ensemble captures ISCCP well, where the CRF mean bias is less than $5 \mathrm{Wm}^{-2}$ and NLWS is in between SRB and CERES, while the respective min-max range is about 10 and $5 \mathrm{Wm}^{-2}$. Consequently, regional climate responses differ substantially among the radiation packages, where the min-max range is about $0.5 \mathrm{~mm} \mathrm{day}^{-1}$ for precipitation in summer and about $1{ }^{\circ} \mathrm{C}$ for surface temperature around the year. The precipitation rmse ensemble mean and min-max range also contain a strong seasonal cycle resembling those of SW flux and CRF, while the temperature rmse seasonality is weak just like that of LW flux and CRF.

Figure 10 compares the spatial frequency distributions of CWRF monthly biases during June, July, and August 2004 over all the US land grids for the same quantities listed above. These months of the year are identified with maximum model biases and spreads among radiation packages. The peak frequency occurring more around the zero line indicates that the respective model simulation has more grids of smaller differences from observations and hence is more realistic overall. Except for precipitation, all other variables show important contrasts among the packages. Clearly cam is an outlier, 

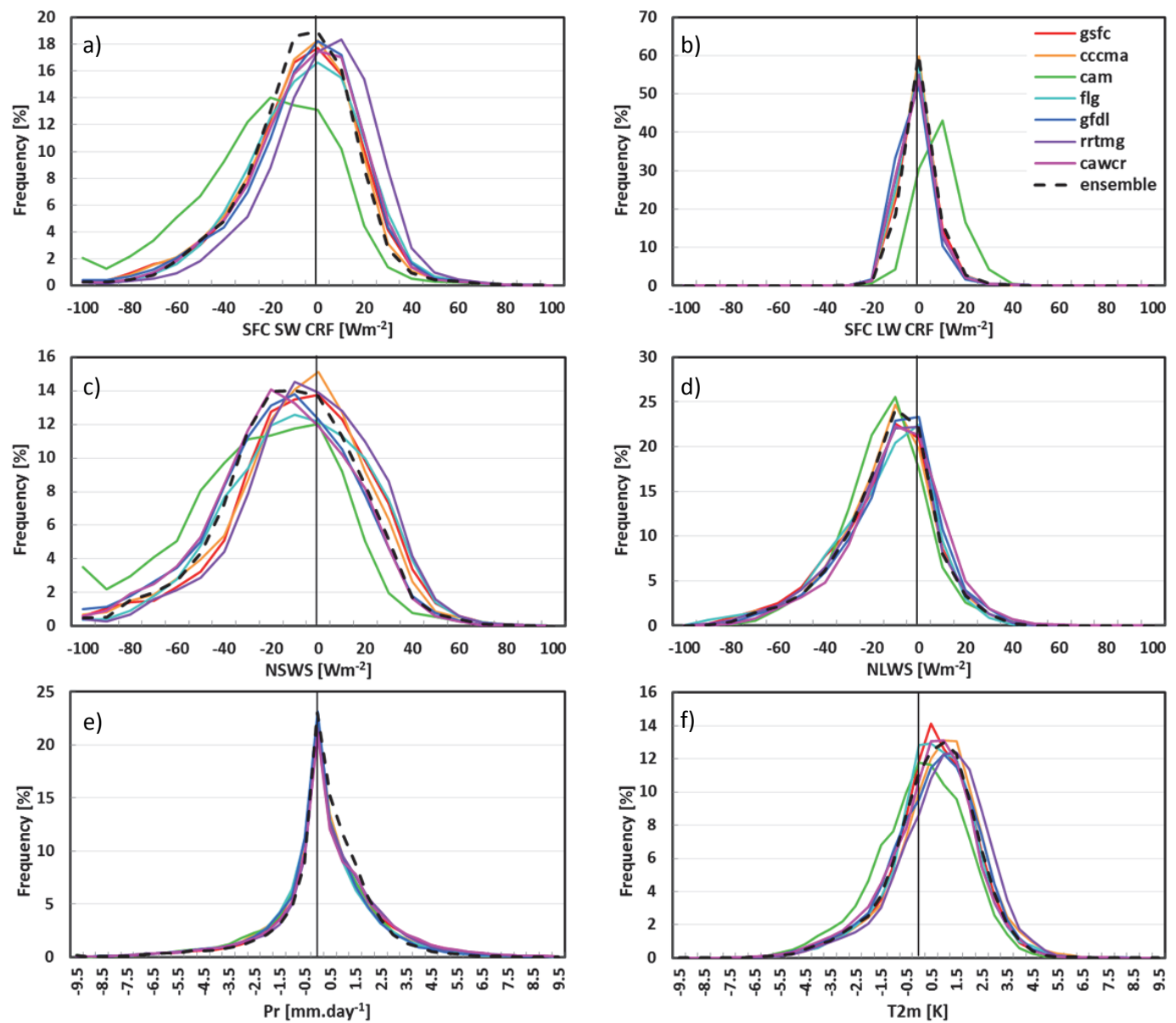

Fig. 10. Spatial frequency distributions of CWRF biases in surface net SW (left) and LW (right) CRFs (a, b), net radiative fuxes (c, d), Pr (e) and T2m (f) among the seven major radiation packages. The statistics are based on monthly means during June, July, and August 2004 over all US land grids.

with its distributions skewed far away from the zero line, indicating more frequent occurrences of larger negative biases in NSWS, NLWS, and SW CRF but opposite biases in LW CRF. To a lesser degree, rrtmg also performs somewhat poorly, with its distribution skewed oppositely from cam. As a result, the CWRF simulated surface temperatures are generally warmer by using rrtmg than cam. The overall CWRF performance is comparable among other five packages. The ensemble mean of all the seven packages tends to reduce the overall biases. But the mean local biases in radiative quantities are still very large. The ranges between the lower and upper 10th percentiles are -38.3 to $+17.8 \mathrm{Wm}^{-2}$ for $\mathrm{SW}$ $\mathrm{CRF}$ and -48.1 to $+22.8 \mathrm{Wm}^{-2}$ for NSWS. The corresponding $\mathrm{LW}$ values are -7.6 to +9.0 and -40.2 to $+7.3 \mathrm{Wm}^{-2}$. The resulting biases in regional climate responses are also substantial, with the ranges of -1.63 to $+2.24 \mathrm{~mm} \mathrm{day}^{-1}$ for precipitation and -1.61 to $+2.55^{\circ} \mathrm{C}$ for temperature. There remains large room for improvement in cloud, aerosol, and radiation representations and their interactions with climate.

\section{Discussion and conclusion}

The CAR ensemble modeling system has been developed to incorporate the major complete radiation packages available from the latest weather/climate models used in the key operational centers and research institutions worldwide, disassemble each package into cloud, aerosol, and radiation components, and then couple all built-in and other parameterization schemes into a single interactive system for consistent and fully exchangeable execution of all possible solutions to cloud, aerosol, and radiation effects. It also includes a common utility for specification of external forcing factors such as solar insolation, Earth orbit variations, GHG concentrations, aerosol loadings, surface albedo, surface emissivity, and topographic impacts. The system can currently model over $10^{18}$ combinations of alternate schemes for cloud properties (cover, water, radius, optics, geometry), aerosol properties (type, profile, optics), radiation transfers (solar, infrared), and their interactions. Not all of these variations are practically applicable in the current GCMs that require system 
tuning for realistic total radiative balance in order to contain climate drift. CAR can be coupled with a climate model that predicts the cloud and aerosol lifecycles to complete the full interactions among cloud, aerosol, radiation, and climate and thus enable a more credible probabilistic climate prediction or climate change projection, including the likelihood and uncertainty.

Given the limited observations and physical understanding that underpin the parameterization development, none of the CAR ensemble members fully represents observed phenomena over the globe. This study conducts, and compares against standard references or best available observations, over 2000 global offline and regional CWRF online (coupled) simulations under realistic climate conditions in order to demonstrate the wide range of outcomes that may result from the choices of the cloud, aerosol, and radiation schemes commonly used in the current leading climate models. The selection is a very limited subset of the CAR ensemble, including 64 cloud property (cover, radius, optics) plus 5 overlap (geometry) schemes, 3 aerosol optical property schemes, and 7 major radiation transfer schemes. Key findings from these comparisons include the following:

1. As compared against the LBL references, the selected CAR radiation transfer schemes achieves high accuracy, producing a mean bias of $\pm 1 \%\left(-4.5\right.$ to $\left.+3.5 \mathrm{Wm}^{-2}\right)$ $\mathrm{LW}$ and -15 to $+5 \%\left(-14\right.$ to $\left.+10 \mathrm{Wm}^{-2}\right) \mathrm{SW}$ for all CIRC standard cases; the discrepancies among various radiation and cloud schemes are about $\pm 5 \%$ (21$25 \mathrm{Wm}^{-2}$ ) due to water vapor absorption treatment and larger (up to $40 \mathrm{Wm}^{-2} \mathrm{SW}$ ) due to cloud optical property parameterization. Smallest errors are generally not identified with the default combination of the radiation transfer and cloud optical property schemes in the original packages, and no single cloud optical property scheme works best with all radiation transfer schemes. Thus, the existing radiation packages have large room for improvement by optimally combining radiation transfer with cloud property schemes.

2. Future projections of the GHG radiative forcing depend on cloud and radiation schemes, and have a greater diversity for a higher emissions scenario (tripled from RCP2.6 to RCP8.5). Clouds decrease the GHG radiative forcing and its model spread, with a $50 \%$ reduction in both from clear sky for RCP8.5 in the year 2100 using a typical midlatitude atmospheric condition. The result indicates that the estimate based on a single radiation transfer or cloud property scheme does not depict the actual uncertainty range in calculating the GHG forcing.

3. Estimates of aerosol direct effects have a large spread due to the choices of radiation, cloud, and aerosol schemes. Under the present-day aerosol loading, the spread in global mean aerosol SW effect at TOA on av- erage for January and July 2004 is less than $1 \mathrm{Wm}^{-2}$ among the radiation or cloud schemes selected, but larger than $6.5 \mathrm{Wm}^{-2}$ due to aerosol optical property parameterization. Approximately $27 \%$ of the 1792 combinations among the selected cloud, aerosol, and radiation schemes produce TOA net total radiative fluxes within the observational uncertainty range. This subset of the configurations as constrained by observations gives an averaged TOA global mean aerosol direct effect of -5.02 and $-3.10 \mathrm{Wm}^{-2}$ for clear sky and all sky, respectively. The result differs little from the estimate based on the rest configurations without the observational constraint. The corresponding standard deviations from the constrained subset are 0.45 and $0.34 \mathrm{Wm}^{-2}$. The total uncertainty illustrated in this study is significantly larger than previous estimates, which are about $0.2 \mathrm{Wm}^{-2}$ in terms of the clear-sky standard deviation (Yu et al., 2006; IPCC 2007). Such a model result spread, however, may still be underestimated since only very few aerosol schemes, especially for the optical property parameterization, are compared.

4. Observational uncertainties are nontrivial, where the best available satellite products differ by $0.05-0.1$ in cloud cover, and $5-10 \mathrm{Wm}^{-2}$ in all-sky radiative fluxes and $5-15 \mathrm{Wm}^{-2}$ for CRFs at TOA or surface, as averaged in July 2004 over $60^{\circ} \mathrm{S}-60^{\circ} \mathrm{N}$. The existing cloud and radiation schemes produce large errors, including cloud cover overestimates of 0.2 in the tropics, and radiative fluxes biases of about $\pm 30 \mathrm{Wm}^{-2}$ in SW and $\pm 10 \mathrm{Wm}^{-2}$ in LW. A substantial spread is simulated among the selected CAR members: $30-60 \mathrm{Wm}^{-2}$ varying in LW or SW all-sky fluxes. This spread is caused mostly by CRF differences, which are respectively attributed to cloud overlap and other properties (cover, radius, optics), by about $20-25$ and $20-40 \mathrm{Wm}^{-2}$ in SW, and about 5-10 and $10 \mathrm{Wm}^{-2}$ in LW. The ensemble frequency distribution is skewed far away from the observational bound, whereas there exists a tendency of common model tuning toward one dataset (ISCCP). Even by applying the conventional tuning constraint on TOA fluxes, the subset model spreads are still notably greater than the observational uncertainty ranges, especially for surface CRFs. The result suggests that the prevailing schemes are likely insufficient in variety and biased in a significant way. It is also found that the ensemble mean reduces overall model departures from observations.

5. CWRF regional climate simulations are very sensitive to the CAR configurations. Based on the seven major radiation packages of the original configurations, the ensemble mean shows systematic underestimates of 10$25 \mathrm{Wm}^{-2}$ over the US land in summer surface SW net flux due to excessive CRF as compared with ISCCP, but still falls within the observational bound by other satellite products. The spread among the packages are, 
however, greater than that bound. Better performance is obtained for LW, with CRF mean biases of less than $5 \mathrm{Wm}^{-2}$ and min-max ranges of $10 \mathrm{Wm}^{-2}$. These radiative forcing differences result in substantial spreads in regional climate responses, with the US land average of $0.5 \mathrm{~mm} \mathrm{day}^{-1}$ for summer precipitation and $1{ }^{\circ} \mathrm{C}$ for annual surface temperature. The ensemble mean of all the seven packages tends to reduce the overall biases. But local biases are still very large, requiring improvement in cloud, aerosol, and radiation representations and their interactions with climate.

In summary, the CAR ensemble modeling system provides a unique tool to determine the probability distributions of GHG, aerosol, and cloud radiative forcing predictions, and more importantly attribute specific key factors for model biases (from observations) and inter-model disparities. This study is for demonstration purposes only, where a small number of the CAR members are used in a few simple experiments. The exact quantities listed above for model biases and inter-model discrepancy ranges do not represent the outcome of the full CAR ensemble, and are expected to change when a more comprehensive subset of the ensemble as constrained by observations is used. More thorough investigations are warranted to obtain a credible estimate of these radiative forcings and their uncertainties in a global perspective under an equilibrium state. However, the main conclusion drawn from the present study will hold: the quantification of these forcings and impacts on climate strongly depends on the choices of the cloud, aerosol, and radiation schemes. The CAR ensemble is superior to any single radiation package and provides a unique system to integrate, and thus facilitate intercomparison and better understanding of, the numerical representations for interactions among cloud, aerosol, and radiation processes commonly used in climate models.

A challenging issue in general applications of the CAR system is how to reduce the ensemble toward a computationally feasible size and select representative members that capture observed characteristics. The initial reduction is being done by standalone CAR tests driven by CRM simulations of field campaigns (Wu et al., 2007; Wu and Liang, 2005) and high-resolution North American Regional Reanalysis (Mesinger et al., 2006) along with best available observations to first screen off a significant number of the versions that produce relatively large errors, and then eliminate those that are highly dependent of each other. This will reduce the ensemble to include a manageable size $(\sim 500)$ of the relatively independent members that best match observations and contain data uncertainty bounds. That reduced suite will form the basis for constructing the optimized physics ensemble (OPE) with varying weights on its members' performance, by which the CAR-coupled models can cost effectively and most realistically simulate observed cloud-aerosol-radiation interactions, and, in general, climate variations. This suite will also account for the likely spread in climate sensitivi- ties among GCMs that are associated with cloud-aerosolradiation interactions and feedbacks, and consequently the perceivable uncertainty range in climate change projections.

The CAR system has a unique advance in the structured CPU time distribution (not shown). The cloud and aerosol drivers consume less than $5 \%$, while the radiation driver takes over $95 \%$, in which less than $10 \%$ is used by the three couplers and the rest (70-90\%) by the radiative transfer part alone. For the final radiative fluxes and heating rates, however, the most expensive radiative transfer part produces insignificant differences between the radiation packages, whereas the cloud and aerosol drivers plus the three couplers contribute most of the sensitivities. The former has $\sim 10^{2}$ different combinations of solar and infrared radiative transfer schemes, while the latter contains over $10^{16}$ variations representing cloud and aerosol properties and interactions. This design enables the likely range of uncertainties in modeling cloud-aerosol-radiation interactions to be resolved mostly by comparing the inexpensive yet greatly variable part of the packages. As such, the cost-effective OPE can be constructed from a representative suite of the core cloud and aerosol parameterizations that are computationally inexpensive but account for most of the CAR sensitivities in coupling with the single most comprehensive and accurate radiative transfer scheme. We will seek a probabilistic solution to this OPE for computational efficiency. For example, we can define the frequency distributions of cloud and aerosol properties from the whole suite of the OPE predictions and/or instantaneous results at every dynamic step, which are then provided for the cloud plus aerosol generator to allocate the subcell or subcolumn inputs for the mosaic or McICA radiative transfer calculations. Such system development and broader applications are our ongoing research topics.

Acknowledgements. We thank Ming-Dah Chou, Jiangnan Li, Jason Cole, Zhian Sun, Qiang Fu, Kuo-Nan Liou, Y. Gu, Michael J. Iacono, Venkatachalma Ramaswamy, William Collins, Catherine C. Chuang, Steve Ghan, Jerome Fast, Wei-Kuo Tao, Larry Di Girolamo, and Guangyu Zhao for providing source codes of their radiation packages, datasets, and guidance on model implementation. We also thank Shenjian Su for assistance in conducting model runs. This work was supported by the US Department of Energy (DOE) Office of Biological and Environmental Research (BER) DESC0007169. During the initial period (2008-2009), Feng Zhang was partially supported by China's National Natural Science Foundation 40605026 and the NOAA Education Partnership Program (EPP) COM Howard 631017. The ERA-Interim data were obtained from the ECMWF, and the ISCCP, SRB, and CERES products were taken from the NASA Langley Research Center.

Edited by: Q. Fu 
Table 5. Abbreviations and acronyms

\begin{tabular}{|c|c|}
\hline $1-\mathrm{D}$ & One-dimensional \\
\hline 3-D7 & Three-dimensional \\
\hline AER & Atmospheric and Environmental Research \\
\hline AEROCOM & The Aerosol Model Intercomparison Initiative \\
\hline AMF & ARM Mobile Facility \\
\hline AOD & Aerosol optical depth \\
\hline ARM & Atmospheric Radiation Measurement \\
\hline CAM & NCAR Community Atmosphere Model \\
\hline CAM-Chem & CAM with interactive chemistry model \\
\hline cam & The radiation transfer scheme from CAM \\
\hline CAR & Cloud-aerosol-radiation ensemble modeling system \\
\hline CAWCR & The Centre for Australian Weather and Climate Research \\
\hline cawcr & The radiation transfer scheme from CAWCR \\
\hline cbl & Scheme for boundary cloud fraction \\
\hline $\mathrm{ccb}$ & Scheme for convective cloud cover fraction \\
\hline CCCMA & Canadian Centre for Climate Modelling and Analysis \\
\hline cccma & The radiation transfer scheme from CCCMA \\
\hline cci & Scheme for cirrus fraction \\
\hline $\mathrm{CCN}$ & Cloud condensation nuclei \\
\hline $\operatorname{ccs}$ & Scheme for stratiform cloud cover fraction \\
\hline CERES & Cloud and the Earth's Radiant Energy System \\
\hline CHARTS & Code for High resolution Accelerated Radiative Transfer and Scattering \\
\hline CIRC & Continual Intercomparison of Radiation Codes \\
\hline CMIP5 & Coupled Model Intercomparison Project Phase 5 \\
\hline CMAQ & Community Multiscale Air Quality \\
\hline $\mathrm{CRF}$ & Cloud radiative forcing \\
\hline CRM & Cloud-resolving model \\
\hline ctot & Scheme for horizontal total cloud cover fraction \\
\hline CWRF & Climate extension of the Weather Research and Forecasting model \\
\hline cwp & Cloud water path \\
\hline dei & Cloud ice effective particle size \\
\hline DOE & US Department of Energy \\
\hline EBAF & CERES Energy Balanced and Filled \\
\hline ECMWF & European Centre for Medium-Range Weather Forecasts \\
\hline ERI & The Global Interim ECMWF Reanalysis \\
\hline flg & $\mathrm{Fu}-\mathrm{Liou}-\mathrm{Gu}$ radiation transfer scheme \\
\hline GCM & General circulation model \\
\hline GEWEX & Global Energy and Water Cycle Experiment \\
\hline GEOS & NASA Goddard Earth Observing System \\
\hline GEOS-Chem & GEOS with interactive chemistry model \\
\hline GFDL & NOAA's Geophysical Fluid Dynamics Laboratory \\
\hline gfdl & Radiation transfer scheme from GFDL \\
\hline GHG & Greenhouse gas \\
\hline GSFC & NASA's Goddard Space Flight Center \\
\hline gsfc & The radiation transfer scheme from GSFC with Liang's modifications \\
\hline ICA & Independent column approximation \\
\hline IPCC & Intergovernmental Panel on climate Change \\
\hline ISCCP & International Satellite Cloud Climatology Project \\
\hline IWC & Cloud ice water content \\
\hline LBL & Line by line \\
\hline LBLRTM & Line-by-line radiative transfer model \\
\hline LW & Longwave \\
\hline LWC & Cloud liquid water content \\
\hline lwi & LW cloud ice optical property scheme \\
\hline lwl & LW cloud liquid optical property scheme \\
\hline
\end{tabular}


Table 5. Continued.

\begin{tabular}{|c|c|}
\hline LWUPT & LW upwelling fluxes at TOA \\
\hline LWDNS & LW downwelling fluxes at the surface \\
\hline MC & Monte Carlo \\
\hline McICA & Monte Carlo independent column approximation \\
\hline MISR & Multi-angle Imaging SpectroRadiometer \\
\hline MLS & Midlatitude summer atmospheric profile \\
\hline MODIS & Moderate Resolution Imaging Spectroradiometer \\
\hline NASA & National Aeronautics and Space Administration \\
\hline NCAR & National Center for Atmospheric Research \\
\hline NCEP & National Centers for Environmental Prediction \\
\hline NLWS & NET LW fluxes at the surface \\
\hline NIR & Near-infrared spectra \\
\hline NOAA & National Oceanic and Atmospheric Administration \\
\hline NSA & Northern slope of Alaska \\
\hline NSWS & NET SW fluxes at the surface \\
\hline OPAC & Optical Properties of Aerosols and Clouds \\
\hline OPE & Optimized physics ensemble \\
\hline ovp1 & Maximum/random vertical association between adjacent/non-adjacent cloud layers \\
\hline ovp2 & Mixed overlap among high/middle/low bulk cloud layers \\
\hline ovp3 & Random overlap \\
\hline ovp4 & Mosaic method \\
\hline ovp5 & McICA method \\
\hline PDF & Probability distribution function \\
\hline PPE & Perturbed physics ensemble \\
\hline PYE & Pt. Reyes (California) \\
\hline rad & Radiation transfer scheme \\
\hline rad_ext & External module for radiation package \\
\hline $\mathrm{RCP}$ & Representative concentration pathway \\
\hline RCP8.5 & Rising radiative forcing pathway to $8.5 \mathrm{Wm}^{-2}$ in 2100 \\
\hline RCP6.0 & Stabilization radiative forcing pathway to $6.0 \mathrm{Wm}^{-2}$ in 2100 \\
\hline $\mathrm{RCP} 4.5$ & Stabilization radiative forcing pathway to $4.5 \mathrm{Wm}^{-2}$ in 2100 \\
\hline $\mathrm{RCP} 2.6$ & Strong mitigation radiative forcing pathway to $2.6 \mathrm{Wm}^{-2}$ in 2100 and decline \\
\hline $\mathrm{RCM}$ & Regional climate model \\
\hline rel & Cloud liquid effective particle radius \\
\hline $\mathrm{RF}$ & Radiative forcing \\
\hline rmse & Root-mean-square error \\
\hline $\operatorname{rrtmg}$ & AER rapid radiative transfer model for application to GCMs \\
\hline SFC & Ground surface \\
\hline SGP & Southern Great Plains \\
\hline SRB & NASA/GEWEX Surface Radiation Budget \\
\hline SSA & Single-scattering albedo \\
\hline SW & Shortwave \\
\hline swi & SW cloud ice optical property scheme \\
\hline swl & SW cloud liquid optical property scheme \\
\hline SWUPT & SW upwelling fluxes at TOA \\
\hline SWDNS & SW downwelling fluxes at the surface \\
\hline TOA & Top of atmosphere \\
\hline UKMO & UK Meteorological Office \\
\hline UW & University of Wisconsin \\
\hline VIS & Visible spectra \\
\hline WRF & Weather Research and Forecasting model \\
\hline WRF-Chem & WRF with interactive chemistry model \\
\hline
\end{tabular}




\section{References}

Abdul-Razzak, H. and Ghan, S. J.: A Parameterization of aerosol activation 3, Sectional representation, J. Geophy. Res., 107, 4026, doi:10.1029/2001JD000483, 2002.

Astin, I. and Di Girolamo, L.: The relationship between $\alpha$ and the cross-correlation of cloud fraction, Quart. J. Roy. Metero. Soc., 132, 2475-2478, 2006.

Barker, H. W., Pincus, R., and Morcrette, J.-J.: The Monte-Carlo Independent Column Approximation: Application within largescale models. Paper presented at GCSS/ARM Workshop on the Representation of Cloud Systems in Large-Scale Models, Kananaskis, Al, Canada, 2002.

Barker, H. W., Stephens, G. L., Partain, P. T., Bergman, J. W., Bonnel, B., Campana, K., Clothiaux, E. E., Clough, S., Cusack, S., Delamere, J., Edwards, J., Evans, K. F., Fouquart, Y., Freidenreich, S., Galin, V., Hou, Y., Kato, S., Li, J., Mlawer, E., Morcrette, J.J., O’Hirok, W., Räisänen, P., Ramaswamy, V., Ritter, B., Rozanov, E., Schlesinger, M., Shibata, K., Sporyshev, P., Sun, Z., Wendisch, M., Wood, N., and Yang, F.: Assessing 1D atmospheric solar radiative transfer models: Interpretation and handling of unresolved clouds, J. Climate, 16, 2676-2699, 2003.

Bauer, S. E. and Menon, S.: Aerosol direct, indirect, semidirect, and surface albedo effects from sector contributions based on the IPCC AR5 emissions for preindustrial and present-day conditions, J. Geophys. Res., 117, D01206, doi:10.1029/2011JD016816, 2012.

Berger, A., Loutre, M., and Tricot, C.: Insolation and Earth's orbital periods, J. Geophys. Res., 98, 10341-10362, 1993.

Bergman, J. W. and Rasch, P. J.: Parameterizing vertically-coherent cloud distributions, J. Atmos. Sci., 59, 2165-2182, 2002.

Bony, S., Colman, R., Kattsov, V. M., Allan, R. P., Bretherton, C. S., Dufresne, J. L., Hall, A., Hallegatte, S., Holland, M. M., Ingram, W., Randall, D. A., Soden, B. J., Tselioudis, G., and Webb, M. J.: How well do we understand and evaluate climate change feedback processes?, J. Climate, 19, 3445-3482, 2006.

Briegleb, B. P.: Delta-Eddington approximation for solar radiation in the NCAR Community Climate Model, J. Geophys. Res., 97, 7603-7612, 1992.

Cahalan, R. F., Ridgway, W., Wiscombe, W. J., Bell, T. L., and Snider, J. B.: The albedo of fractal stratocumulus clouds, J. Atmos. Sci., 51, 2434-2455, 1994.

Cairns, B., Lacis, A. A., and Carlson, B. E.: Absorption within inhomogeneous clouds and its parameterization in general circulation models, J. Atmos. Sci., 57, 700-714, 2000.

Cash, B. A., Schneider, E. K., and Bengtsson, L.: Origin of climate sensitivity differences: role of selected radiative processes in two GCMs, Tellus A, 59, 155-169, 2007.

Cess, R. D., Zhang, M. H., Ingram, W. J., Potter, G. L., Alekseev, V., Barker, H. W., Cohen-Solal, E., Colman, R. A., Dazlich, D. A., Del Genio, A. D., Dix, M. R., Dymnikov, V., Esch, M., Fowler, L. D., Fraser, J. R., Galin, V., Gates, W. L., Hack, J. J., Kiehl, J. T., Le Treut, H., Lo, K. K. W., McAvaney, B. J., Meleshko, V. P., Morcrette, J. J., Randall, D. A., Roeckner, E., Royer, J. F., Schlesinger, M. E., Sporyshev, P. V., Timbal, B., Volodin, E. M., Taylor, K. E., Wang, W., and Wetherald, R. T.: Cloud feedback in atmosphere general circulation models: an update, J. Geophys. Res., 101, 12791-12794, 1996.

Chou, M.-D. and Suarez, M. J.: A solar radiation parameterization for atmospheric studies, [Last revision on March 2002] Technical
Report Series on Global Modeling and Data Assimilation, edited by: Suarez, M. J., NASA/TM-1999-104606, Vol. 15, Goddard Space Flight Center, Greenbelt, MD, 42 pp., 1999.

Chou, M.-D., Suarez, M. J., Ho, C.-H., Yan, M. M.-H., and Lee, K.-T.: Parameterizations for cloud overlapping and shortwave single-scattering properties for use in general circulation and cloud ensemble models, J. Climate, 11, 202-214, 1998.

Chou, M.-D., Suarez, M. J., Liang, X.-Z., and Yan, M. M.-H.: A thermal infrared radiation parameterization for atmospheric studies, [Last revision on July 2002] Technical Report Series on Global Modeling and Data Assimilation, edited by: Suarez, M. J., NASA/TM-2001-104606, Vol. 19, Goddard Space Flight Center, Greenbelt, MD, 56 pp., 2001.

Chu, D.A., Kaufman, Y.J., Ichoku, C., Remer, L. A., Tanre, D., and Holben, B. N.: Validation of MODIS aerosol optical depth retrieval over land, Geophys. Res. Lett., 29, 8007, doi:10.1029/2001GL013205, 2002.

Chuang, C. C., Penner, J. E., Prospero, J. M., Grant, K. E., Rau, G. H., and Kawamoto, K.: Cloud susceptibility and the first aerosol indirect forcing: Sensitivity to black carbon and aerosol concentrations, J. Geophy. Res., 107, 4564, doi:10.1029/ 2000JD000215, 2002.

Clough, S. A., Iacono, M. J., and Moncet, J.-L.: Line-by-line calculations of atmospheric fluxes and cooling rates: Application to water vapor, J. Geophys. Res., 97, 15761-15785, 1992.

Clough, S. A., Shephard, M. W., Mlawer, E. J., Delamere, J. S., Iacono, M. J., Cady-Pereira, K., Boukabara, S., and Brown, P. D.: Atmospheric radiative transfer modeling: A summary of the AER codes, J. Quant. Spectrosc. Radiat. Transfer, 91, 233-244, 2005.

Collins, W. D.: Parameterization of generalized cloud overlap for radiative calculations in general circulation models, J. Atmos. Sci., 58, 3224-3242, 2001.

Collins, W. D., Rasch, P. J., Boville, B. A., Hack, J. J., McCaa, J. R., Williamson, D. L., Kiehl, J. T., Briegleb, B., Bitz, C., Lin, S.-J., Zhang, M., and Dai, Y.: Description of the NCAR Community Atmosphere Model (CAM 3.0), NCAR Technical Note, NCAR/TN-464+STR, 226 pp., 2004.

Collins, W. D., Ramaswamy, V., Schwarzkopf, M. D., Sun, Y., Portmann, R. W., Fu, Q., Casanova, S. E. B., Dufresne, J.-L., Fillmore, D. W., Forster, P. M. D., Galin, V. Y., Gohar, L. K., Ingram, W. J., Kratz, D. P., Lefebvre, M.-P., Li, J., Marquet, P., Oinas, V., Tsushima, Y., Uchiyama, T., and Zhong, W. Y.: Radiative forcing by well-mixed greenhouse gases: Estimates from climate models in the Intergovernmental Panel on Climate Change (IPCC) Fourth Assessment Report (AR4), J. Geophys. Res., 111, D14317, doi:10.1029/2005JD006713, 2006.

Cox, S. J., Stackhouse, P. W. Jr., Gupta, S. K., Mikovitz, J. C., Chiacchio, M., and Zhang, T.: The NASA/GEWEX Surface Radiation Budget Project: Results and analysis. In IRS 2004: Current Problems in Atmospheric Radiation, paper presented at the International Radiation Symposium, Busan, Korea, edited by: Fischer, H. and Soon, B.-J., Deepak, A., Publishing, 419 pp., 2004.

Di Girolamo, L. and Davies, R.: The image navigation cloud mask for the Multi-angle Imaging SpectroRadiometer (MISR),. J. Atmos. Oceanic Tech., 12, 1215-1228, 1995.

Del Genio, A. D., Wolf, A. B., and Yao, M.-S.: Evaluation of regional cloud feedbacks using single-column models, J. Geophys. Res., 110, D15S13, doi:10.1029/2004JD005011, 2005. 
Dobbie, J., Li, J., and Chýlek, P.: Two- and four-stream optical properties for water clouds and solar wavelengths, J. Geophys. Res., 104, 2067-2079, 1999.

Ebert, E. E. and Curry, J. A.: A parameterization of cirrus cloud optical properties for climate models, J. Geophys. Res., 97, 38313836, 1992.

Edwards, J. M., Havemann, S., Thelen, J. C., and Baran, A. J.: Parameterization for the radiative properties of ice crystals: Comparison with existing schemes and impact in a GCM, Atmos. Res., 83, 19-35, 2007.

Ellingson, R. G., Ellis, J., and Fels, S.: The intercomparison of radiation codes used in climate models: Long wave results, J. Geophys. Res., 96, 8929-8953, 1991.

Ferrier, B. S., Lin, Y., Black, T., Rogers, E., and DiMego, G.: Implementation of a new grid-scale cloud and precipitation scheme in the NCEP ETA model, Preprints at 15th Conference on Numerical Weather Prediction, San Antonio, TX, Amer. Meteor. Soc., 280-283, 2002.

Flanner, M., Zender, C., Randerson, J., and Rasch, P.: Present-day climate forcing and response from black carbon in snow, J. Geophys. Res., 112, D11202, doi:10.1029/2006 JD008003, 2007.

Fouquart, Y., Bonnel, B., and Ramaswamy, V.: Intercomparing shortwave radiation codes for climate studies, J. Geophys. Res., 96, 8955-8968, 1991.

Freidenreich, S. M. and Ramaswamy, V.: A new multiple-band solar radiative parameterization for general circulation models, J. Geophys. Res., 104, 31389-31409, 1999.

Fu, Q. and Liou, K.N.: On the correlated k-distribution method for radiative transfer in nonhomogeneous atmospheres, J. Atmos. Sci., 49, 2139-2156, 1992.

Fu, Q., Liou, K. N., Cribb, M. C., Charlock, T. P., and Grossman, A.: Multiple scattering parameterization in thermal infrared radiative transfer, J. Atmos. Sci., 54, 2799-2812, 1997.

Fu, Q., Yang, P., and Sun, W. B.: An accurate parameterization of the infrared radiative properties of cirrus clouds for climate models, J. Climate, 11, 2223-2237, 1998.

Geleyn, J.-F. and Hollingsworth, A.: An economical analytical method for the computation of the interaction between scattering and line absorption of radiation, J. Atmos. Phys., 52, 1-16, 1979.

Gu, Y., Liou, K. N., Ou, S. C., and Fovell, R.: Cirrus cloud simulations using WRF with improved radiation parameterization and increased vertical resolution, J. Geophys. Res., 116, D06119, doi:10.1029/2010JD014574, 2011.

Hess, M., Koepke, P., and Schult, I.: Optical Properties of Aerosols and Clouds: The Software Package OPAC, Bull. Amer. Meteor. Soc., 79, 831-844, 1998.

Hogan, R. J. and Illingworth, A.J.: Deriving cloud overlap statistics from radar, Q. J. R. Meteorol. Soc., 126, 2903-2909, 2000.

$\mathrm{Hu}, \mathrm{Y}$. X. and Stamnes, K.: An accurate parameterization of the radiative properties of water clouds suitable for use in climate models, J. Climate, 6, 728-742, 1993.

Iacono, M. J., Delamere, J. S., Mlawer, E. J., Shephard, M. W., Clough, S. A., and Collins, W. D.: Radiative forcing by long-lived greenhouse gases: Calculations with the AER radiative transfer models, J. Geophys. Res., 113, D13103, doi:10.29/2008JD009944, 2008.

Ichikawa, H., Masunaga, H., Tsushima, Y., and Kanzawa, H.: Reproducibility by climate models of cloud radiative forcing asso- ciated with tropical convection, J. Climate, 25, 1247-1262, 2012.

IPCC (Intergovernmental Panel on Climate Change): Climate Change 2007: The Physical Science Basis, Solomon S., Qin D., Manning, M., Marquis, M., Averyt, K., Tignor, M.M.B., Miller, H.L. Jr., and Chen, Z., Contribution of Working Group I to the Fourth Assessment Report of the IPCC, Cambridge University Press, New York, 2007.

Kahn, R. A., Gaitley, B. J., Martonchik, J. V., Diner, D. J., Crean, K. A., and Holben, B.: Multiangle Imaging Spectroradiometer (MISR) global aerosol optical depth validation based on 2 years of coincident Aerosol Robotic Network (AERONET) observations, J. Geophys. Res., 110, D10S04, doi:10.29/2004JD004706, 2005.

Kahn, R. A., Garay, M. J., Nelson, D. L., Yau, K. K., Bull, M. A., Gaitley, B. J., Martonchik, J. V., and Levy, R. C.: Satellite-derived aerosol optical depth over dark water from MISR and MODIS: Comparisons with AERONET and implications for climatological studies, J. Geophys. Res., 112, D18205, doi:10.29/2006JD008175, 2007.

Kay, J., Hillman, B., Klein, S., Zhang, Y., Medeiros, B., Pincus, R., Gettelman, A., Eaton, B., Boyle, J., Marchand, R., and Ackerman, T.: Exposing global cloud biases in the Community Atmosphere Model (CAM) using satellite observations and their corresponding instrument simulators, J. Climate, 25, 5190-5207, 2012.

Kiehl, J. T., Hack, J. J., Bonan, G. B., Boville, B. A., Briegleb, B. P., Williamson, D. L., and Rasch, P. J.: Description of the NCAR Community Climate Model (CCM3). NCAR Tech. Note, NCAR/TN-420+STR, 143 pp., 1996.

Kiehl, J. T., Hack, J. J., Bonan, G. B., Boville, B. A., Williamson, D. L., and Rasch, P. J.: The National Center for Atmospheric Research Community Climate Model: CCM3, J. Climate, 11, 11311149, 1998.

Li, J.: Accounting for unresolved clouds in a 1-D infrared radiative transfer model, Part I: Solution for radiative transfer, including cloud scattering and overlap, J. Atmos. Sci., 59, 3302-3320, 2002.

Li, J. and Barker, H. W.: A radiation algorithm with correlated-k distribution, Part I: local thermal equilibrium, J. Atmos. Sci., 62, 286-309, 2005

Li, J. and Min, Q. L.: Note and correspondence: parameterization of the optical properties of sulfate aerosols in the infrared, J. Atmos. Sci., 59, 3130-3140, 2002.

Li, J., Wong, J. G. D., Dobbie, J. S., and Chylek, P.: Parameterization of the optical properties of sulfate aerosols, J. Atmos. Sci., 58, 193-209, 2001.

Li, J., Mlawer, E., and Chylek, P.: Parameterization of cloud optical properties for semidirect radiative forcing, J. Geophys. Res., 116, D23212, doi:10.1029/2011JD016611, 2011.

Li, J.-L. F., Waliser, D., Woods, C., Teixeira, J., Bacmeister, J., Chern, J., Shen, B.-W., Tompkins, A., Tao, W.-K., and Köhler, M.: Comparisons of satellites liquid water estimates to ECMWF and GMAO analyses, 20th century IPCC AR4 climate simulations, and GCM simulations, Geophys. Res. Lett., 35, L19710, doi:10.1029/2008GL035427, 2008

Li, J.-L. F., Waliser, D. E., and Jiang, J. H.: Correction to "Comparisons of satellites liquid water estimates to ECMWF and GMAO analyses, 20th century IPCC AR4 climate simulations, and GCM simulations”, Geophys. Res. Lett., 38, L24807, 
doi:10.1029/2011GL049956, 2011a.

Li, J.-L. F., Waliser, D. E., Chen, W.-T., Guan, B., Kubar, T., Stephen, G., Ma, H.-Y., Deng, M., Donner, L., Seman, C., and Horowitz, L.: An observationally-based evaluation of cloud ice water in CMIP3 and CMIP5 GCMs and contemporary reanalyses using contemporary satellite data, J. Geophys. Res., 117, D16105, doi:10.1029/2012JD017640, 2012.

Li, J.-L. F., Waliser, D. E., Stephens, G., Lee, S., L'Ecuyer, T., Kato, S., Loeb, N., and Ma, H.-Y.: Characterizing and understanding radiation budget biases in CMIP3/CMIP5 GCMs, contemporary GCM, and reanalysis, J. Geophys. Res., 118, doi:10.1002/jgrd.50378, 2013.

Liang, X.-Z. and Wang, W.-C.: Cloud overlap effects on general circulation model climate simulations, J. Geophys. Res., 102, 11039-11047, 1997.

Liang, X.-Z. and Wu, X.: Evaluation of a GCM subgrid cloud-radiation interaction parameterization using cloudresolving model simulations, Geophys. Res. Lett., 32, L06801, doi:10.1029/2004GL022301, 2005.

Liang, X.-Z., Wang, W.-C., and Boyle, J. S.: Atmospheric ozone climatology for use in general circulation models, PCMDI Report No. 43, UCRL-MI-125650, 25 pp., 1997.

Liang, X.-Z., Xu, M., Gao, W., Kunkel, K. E., Slusser, J., Dai, Y., Min, Q., Houser, P. R., Rodell, M., Schaaf, C. B., and Gao, F.: Development of land surface albedo parameterization bases on Moderate Resolution Imaging Spectroradiometer (MODIS) data, J. Geophys. Res., 110, D11107, doi:10.1029/2004JD005579, 2005.

Liang, X.-Z., Xu, M., Choi, H.I, Kunkel, K. E., Rontu, L., Geleyn, J.-F., Müller, M. D., Joseph, E., and, Wang, J. X. L.: Development of the regional Climate-Weather Research and Forecasting model (CWRF): Treatment of subgrid topography effects, Paper presented at the 7th Annual WRF User's Workshop, Boulder, CO, 5 pp., 2006.

Liang, X.-Z., Xu, M., Yuan, X., Ling, T., Choi, H.I., Zhang, F., Chen, L., Liu, S., Su, S., Qiao, F., He, Y., Wang, J. X. L., Kunkel, K. E., Gao, W., Joseph, E., Morris, V., Yu, T.-W., Dudhia, J., and Michalakes, J.: Regional Climate-Weather Research and Forecasting Model (CWRF), Bull. Amer. Meteor. Soc., 93, 13631387, doi:10.1175/BAMS-D-11-00180.1, 2012.

Lindner, T. H. and Li, J.: Parameterization of the optical properties for water clouds in the infrared, J. climate, 13, 1797-1805, 2000.

Liou, K.N., Gu, Y., Yue, Q., and McFarguhar, G.: On the correlation between ice water content and ice crystal size and its application to radiative transfer and general circulation models, Geophys. Res. Lett., 35, L13805, doi:10.1029/2008GL033918, 2008.

Lohmann, U. and Feichter, J.: Global indirect aerosol effects: a review, Atmos. Chem. Phys., 5, 715-737, doi:10.5194/acp-5-7152005, 2005.

Manabe, S. and Strickler, R. F.: Thermal equilibrium of the atmosphere with a convective adjustment, Journal of the Atmospheric Sciences, 21, 361-365, 1964.

Martin, G. M., Johnson, D. W., and Spice, A.: The measurement and parameterization of effective radius of droplets in warm stratocumulus clouds. J. Atmos. Sci., 51, 1823-1842, 1994.

Meinshausen, M., Smith, S. J., Calvin, K., Daniel, J. S., Kainuma, M. L. T., Lamarque, J.-F., Matsumoto, K., Montzka, S., Raper, S., Riahi, K., Thomson, A., Velders, G. J. M., and van Vuuren, D. P.: The RCP greenhouse gas concentrations and their extension from 1765 to 2500, Clim. Change, 109, 213-241, 2011.

Mesinger, F., DiMego, G., Kalnay, E., Mitchell, K., Shafran, P., Ebisuzaki, W., Jovic, D., Woollen, J., Rogers, E., Berbery, E., Ek, M., Fan, Y., Grumbine, R., Higgins, W., Li, H., Lin, Y., Manikin, G., Parrish, D., and Shi, W.: North American regional reanalysis, Bull. Amer. Meteor. Soc., 87, 343-360, 2006.

Min, Q. L., and Harrison, L. C.: Cloud properties derived from surface MFRSR measurements and comparison with GOES results at the ARM SGP site, Geophys. Res. Lett., 23, 1641-1644, 1996.

Ming, Y., Ramaswamy, V., Donner, L. J., and Phillips, V. T. J.: A new parameterization of cloud droplet activation applicable to general circulation models, J. Atmos. Sci., 63, 1348-1356, 2006.

Morcrette, J. J., Barker, H. W., Cole, J. N. S., Iacono, M. J., and Pincus, R.: Impact of a new radiation package, McRad, in the ECMWF integrated forecasting system, Mon. Wea. Rev., 136, 4773-4798, 2008.

Moss, R. H., Edmonds, J. A., Hibbard, K. A., Manning, M. R., Rose, S. K., van Vuuren, D. P., Carter, T. R., Emori, S., Kainuma, M., Kram, T., Meehl, G. A., Mitchell, J. F. B., Nakicenovic, N., Riahi, K., Smith, S. J., Stouffer, R. J., Thomson, A. M., Weyant, J. P., and Wilbanks, T. J.: The next generation of scenarios for climate change research and assessment, Nature, 463, 747-756, doi:10.1038/nature08823, 2010.

Müller, M. D. and Scherer, D.: A grid- and subgrid-scale radiation parameterization of topographic effects for mesoscale weather forecast models. Monthly Weather Review, 133, 1431-1442, doi:10.1175/MWR2927.1, 2005.

Murphy, J. M., Sexton, D. M. H., Barnett, D. N., Jones, G. S., Webb, M. J., Collins, M., and Stainforth, D. A.: Quantification of modelling uncertainties in a large ensemble of climate change simulations, Nature, 430, 768-772, 2004.

Nakicenovic, N., Alcamo, J., Davis, G., de Vries, B., Fenhann, J., Gaffin, S., Gregory, K., Grübler, A., Jung, T. Y., Kram, T., La Rovere, E. L., Michaelis, L., Mori, S., Morita, T., Pepper, W., Pitcher, H., Price, L., Riahi, K., Roehrl, A., Rogner, H.-H., Sankovski, A., Schlesinger, M., Shukla, P., Smith, S., Swart, R., Rooijen, van S., Victor, N., and Dadi, Z.: IPCC Special Report on Emissions Scenarios. Cambridge University Press, UK, 570 pp., 2000.

Naud, C. M., Del Genio, A. D., Mace, G. G., Benson, S., Clothiaux, E. E., and Kollias, P.: Impact of dynamics and atmospheric state on cloud vertical overlap, J. Climate, 21, 1758-1770, 2008.

Neale, R. B., Chen, C.-C., Gettelman, A., Lauritzen, P. H., Park, S., Williamson, D. L., Conley, A. J., Garcia, R., Kinnison, D., Lamarque, J.-F., Marsh, D., M., Smith, A. K., Tilmes, S., Vitt, F., Cameron-Smith, P., Collins, W. D., Iacono, M. J., Easter, R. C., Ghan, S. J., Liu, X., Rasch, P. J., and Taylor, M. A.: Description of the NCAR Community Atmosphere Model (CAM 5.0), NCAR Technical NoteNCAR/TN-486+STR, June, 268 pp., 2010.

Nenes, A. and Seinfeld, J. H.: Parameterization of cloud droplet formation in global climate models, J. Geophy. Res., 108, 4415, doi:10.1029/2002JD002911, 2003.

Oreopoulos, L., Mlawer, E., Delamere, J., Shippert, T., Cole, J., Fomin, B., Iacono, M., Jin, Z. H., Li, J. N., Manners, J., Räisänen, P., Rose, F., Zhang, Y. C., Wilson, M. J., and Rossow, W. B.: The continual intercomparison of radiation codes: results from phase I, J. Geophys. Res., 117, D06118, doi:10.1029/2011JD016821, 2012. 
Pincus, R., Barker, H. W., and Morcrette, J.-J.: A fast, flexible, approximate technique for computing radiative transfer in inhomogeneous clouds, J. Geophys. Res., 108D, 4376, doi:10.1029/2002JD003322, 2003.

Pincus, R., Hannay, C., and Evans, K. F.: The accuracy of determining three-dimensional radiative transfer effects in cumulus clouds using ground-based profiling instruments, J. Atmos. Sci., 62, 2284-2293, 2005.

Pincus, R., Batstone, C. P., Hofmann, R. J. P., Taylor, K. E., and Glecker, P. J.: Evaluating the present-day simulation of clouds, precipitation, and radiation in climate models, J. Geophys. Res., 113, D14209, doi:10.1029/2007JD009334, 2008.

Räisänen, P., Barker, H. W., Khairoutdinov, M. F., Li, J., and Randall, D. A.: Stochastic generation of subgrid-scale cloudy columns for large-scale models, Q. J. R. Meteorol. Soc,, 130, 2047-2067, 2004.

Remer, L. A., Tanré, D., Kaufman, Y.J., Ichoku, C., Mattoo, S., Levy, R., Chu, D. A., Holben, B., dubovik, O., Smirnov, A., Martins, J. V., Li, R. R., and Ahmad, Z.: Validation of MODIS aerosol retrieval over ocean, Geophys. Res. Lett., 29, 8008, doi:10.1029/2001GL013204, 2002.

Rossow, W. B., Walker, A. W., Beuschel, D. E., and Roiter, M. D.: International Satellite Cloud Climatology Project (ISCCP) Documentation of New Cloud Datasets. WMO/TD-No. 737, World Meteorological Organization, 115 pp., 1996.

Rossow, W. B., Delo, C., and Cairns, B.: Implications of the observed mesoscale variations of clouds for Earth's radiation budget, J. Climate, 15, 557-585, 2002.

Rossow, W. B., Zhang, Y. C., and Wang, J. H.: A statistical model of cloud vertical structure based on reconciling cloud layer amounts inferred from satellites and radiosonde humidity profiles, J. Climate, 18, 3587-3605, 2005.

Sanderson, B. M.: A multimodel study of parametric uncertainty in predictions of climate response to rising greenhouse gas concentrations, J. Climate, 24, 1362-1377, 2011.

Savijärvi, H., Arola, A., and Räisänen, P.: Short-wave optical properties of precipitating water clouds, Quart. J. Roy. Meteorol. Soc., 123, 883-899, 1997.

Schwarzkopf, M. D. and Ramaswamy, V.: Radiative effects of $\mathrm{CH}_{4}$, $\mathrm{N}_{2} \mathrm{O}$, halocarbons and the foreign-broadened $\mathrm{H}_{2} \mathrm{O}$ continuum: A GCM experiment, J. Geophys. Res., 104, 9467-9488, 1999.

Seemann, S. W., Borbas, E. E., Knuteson, R. O., Stephenson, G. R., and Huang, H.-L.: Development of a global infrared land surface emissivity database for application to clear sky sounding retrievals from multispectral satellite radiance measurements, J. Appl. Meteor. Climatol., 47, 108-123, 2008.

Senkova, A. V., Rontu, L., and Savijärvi, H.: Parametrization of orographic effects on surface radiation in HIRLAM, Tellus, 59, 279291, doi:10.1111/j.1600-0870.2007.00235.x, 2007.

Slingo, A. S.: A GCM parameterization for the shortwave radiative properties of water clouds, J. Atmos. Sci., 46, 1419-1427, 1989.

Slingo, J. M.: The development and verifcation of a cloud prediction scheme for the ECMWF model, Quart. J. Roy. Meteorol. Soc., 113, 899-927, 1987.

Stackhouse, P. W. Jr., Cox, S. J., Gupta, S. K., Chiacchio, M., and Mikovitz, J. C.: The WCRP/GEWEX surface radiation budget project release 2: An assessment of surface fluxes at 1 degree resolution. Paper presented at International Radiation Symposium, St.-Petersburg, Russia, July 24-29, IRS 2000: Current Problems in Atmospheric Radiation, edited by: W. L. Smith and Y. Timofeyev, p. 147, A. Deepak Publishing, 2001.

Stainforth, D. A., Aina, T., Christensen, C., Collins, M., Faull, N., Frame, D. J., Kettleborough, J. A., Knight, S., Martin, A., Murphy, J. M., Piani, C., Sexton, D., Smith, L. A., Spicer, R. A., Thorpe, A. J., and Allen, M. R.: Uncertainty in predictions of the climate response to rising levels of greenhouse gases, Nature, 433, 403-406, 2005.

Stott, P. A. and Kettleborough, J. A.: Origins and estimates of uncertainty in predictions of twenty-first century temperature rise, Nature, 416, 723-726, 2002.

Sun, Z.: Development of the Sun-Edwards-Slingo Radiation Scheme (SES2). In CAWCR Technical Report No. 009, Centre for Australian Weather and Climate Research, Australian Bureau of Meteorology, 94 pp., 2008.

Sun, Z. A. and Rikus, L.: Parametrization of effective radius of cirrus clouds and its verification against observations, Q. J. Royal. Meteor. Soc., 125, 3037-3056, 1999.

Taylor, K. E., Stouffer, R. J., and Meehl, G. A.: A Summary of the CMIP5 Experiment Design, World Climate Research Program, 32 pp., 2009.

Tebaldi, C. and Knutti, R.: The use of the multi-model ensemble in probabilistic climate projections, Phil. Trans. R. Soc. A., 3, 2053-2075, 2007.

Tiedtke, M.: Representation of clouds in large-scale models, Mon. Wea. Rev., 121, 3040-3061, 1993.

Tompkins, A. M.: A prognostic parameterization for the subgridscale variability of water vapor and clouds in large-scale models and its use to diagnose cloud cover, J. Atmos. Sci., 59, 19171942, 2002.

Uppala, S.M., Dee, D.P., Kobayashi, S., Berrisford, P., and Simmons, A.J.: Towards a climate data assimilation system: Status update of ERA-Interim, ECMWF Newsletter, 115, 12-18, 2008.

Waliser, D. E., Li, J.-L. F., Woods, C. P., Austin, R. T., Bacmeister, J., Chern, J., Del Genio, A., Jiang, J. H., Kuang, Z., Meng, H., Minnis, P., Platnick, S., Rossow, W. B., Stephens, G. L., SunMack, S., Tao, W.-K., Tompkins, A. M., Vane, D. G., Walker, C., and Wu, D.: Cloud ice: A climate model challenge with signs and expectations of progress, J. Geophys. Res., 114, D00A21, doi:10.1029/2008JD010015, 2009.

Watanabe, M., Emori, S., Satoh, M., and Miura, H.: A PDF based hybrid prognostic cloud scheme for general circulation models, Clim. Dyn., 33, 795-816, 2009.

Webb, M. J., Senior, C. A., Sexton, D. M. H., Ingram, W. J., Williams, K. D., Ringer, M. A., McAvaney, B. J., Colman, R., Soden, B. J., Gudgel, R., Knutson, T., Emori, S., Ogura, T., Tsushima, Y., Andronova, N., Li, B., Musat, I., Bony, S., and Taylor, K. E.: On the contribution of local feedback mechanisms to the range of climate sensitivity in two GCM ensembles, Clim. Dynam., 27, 17-38, 2006.

Wielicki, B. A., Barkstrom, B., Harrison, E. F., Lee, R., Smith, G., and Cooper, J.: Clouds and the Earth's Radiant Energy System (CERES): An Earth observing system experiment, Bull. Am. Meteorol. Soc., 77, 853-868, 1996.

Wild, M.: Solar radiation budgets in atmospheric model intercomparisons from a surface perspective, Geophys. Res. Lett., 32, L07704, doi:10.1029/2005GL022421, 2005.

Wild, M., Long, C. N., and Ohmura, A.: Evaluation of clear-sky solar fluxes in GCMs participating in AMIP and IPCC-AR4 
from a surface perspective, J. Geophys. Res., 111, D01104, doi:10.1029/2005JD006118, 2006.

Wu, X. and Liang, X.-Z.: Radiative effects of cloud horizontal inhomogeneity and vertical overlap identified from a month-long cloud-resolving model simulation, J. Atmos. Sci., 62, 41054112, 2005.

Wu, X., Liang, X.-Z., and Park, S.: Cloud-resolving model simulations over the ARM SGP. Mon. Wea. Rev., 135, 2841-2853, 2007.

Xu, K.-M. and Randall, D. A.: A semiempirical cloudiness parameterization for use in climate models, J. Atmos. Sci., 53, 30843102, 1996.

Yu, H., Kaufman, Y. J., Chin, M., Feingold, G., Remer, L. A., Anderson, T. L., Balkanski, Y., Bellouin, N., Boucher, O., Christopher, S., DeCola, P., Kahn, R., Koch, D., Loeb, N., Reddy, M. S., Schulz, M., Takemura, T., and Zhou, M.: A review of measurement-based assessments of the aerosol direct radiative effect and forcing, Atmos. Chem. Phys., 6, 613-666, doi:10.5194/acp-6-613-2006, 2006.
Zhang, F., Liang, X.-Z., Li, J., and Zeng, Q.-C.: Dominant roles of subgrid-scale cloud structures in model diversity of cloud radiative effects, J. Geophys. Res., 118, 7733-7749, 2013.

Zhang, M. H., Lin, W. Y., Klein, S. A., Bacmeister, J. T., Bony, S., Cederwall, R. T., Del Genio, A. D., Hack, J.J., Loeb, N. G., Lohmann, U., Minnis, P., Musat, I., Pincus, R., Stier, P., Suarez, M. J., Webb, M. J., Wu, J. B., Xie, S. C., Yao, M.-S., and Zhang, J. H.: Comparing clouds and their seasonal variations in 10 atmospheric general circulation models with satellite measurements, J. Geophys. Res., 110, D15S02, doi:10.1029/2004JD005021, 2005.

Zhang, Y.-C., Rossow, W. B., Lacis, A. A., Oinas, V., and Mishchenko, M. I.: Calculation of radiative fluxes from the surface to top-ofatmosphere based on ISCCP and other global datasets: Refinements of the radiative transfer model and the input data, J. Geophys. Res., 109, D19105, doi:10.1029/2003JD004457, 2004. 